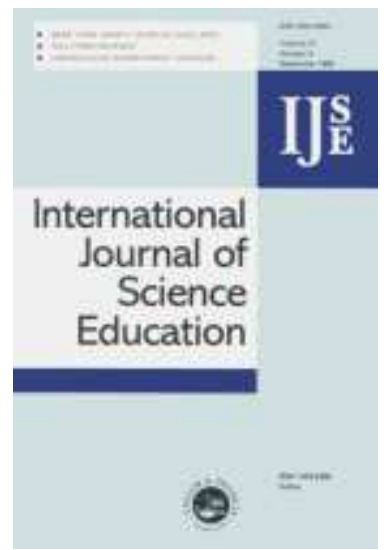

\title{
SIXTH GRADERS' CO-CONSTRUCTION OF EXPLANATIONS OF A DISTURBANCE IN AN ECOSYSTEM: EXPLORING RELATIONSHIPS BETWEEN GROUPING, REFLECTIVE SCAFFOLDING, AND EVIDENCE-BASED EXPLANATIONS
}

\begin{tabular}{|r|l|}
\hline Journal: & International Journal of Science Education \\
\hline Manuscript ID: & TSED-2009-0189.R3 \\
\hline Manuscript Type: & Research Paper \\
\hline Keywords: & evidence-based reasoning, reflective inquiry, middle school \\
\hline Keywords (user): & explanation, scaffolding \\
\hline
\end{tabular}

\section{SCHOLARONE Manuscripts}




\begin{abstract}
We report on a study investigating the relationship between cognitive ability grouping, reflective inquiry scaffolding, and students' collaborative explanations of an ecosystem disturbance which took place when a number of flamingo birds died in a salt lake with nearby intensive human activities. Twenty-six pairs of students from two intact $6^{\text {th }}$ grade classes participated in the study. All students investigated scientific data relating to the ecosystem problem using a web-based learning environment. One class was provided with web-based reflective inquiry scaffolding (WorkSpace) while the other class used PowerPoint. The main data analyzed for this study consisted of each pair's written explanation and task-related artifacts. Findings show that the web-based reflective scaffolding supported students in providing valid evidence in support of their explanations. The analyses of the students' collaborative explanations showed no statistically significant differences that could be attributed to prior achievement between students in the WorkSpace condition, while differences were found between the different cognitive ability pairs in the PowerPoint class. These findings suggest that the WorkSpace scaffolding may have provided more influential support to lower cognitive ability pairs in creating evidence-based explanations.
\end{abstract}

Keywords: explanations, evidence-based reasoning, inquiry-based learning, reflective inquiry scaffolding. 
SIXTH GRADERS' CO-CONSTRUCTION OF EXPLANATIONS OF A

DISTURBANCE IN AN ECOSYSTEM: EXPLORING RELATIONSHIPS BETWEEN

GROUPING, REFLECTIVE SCAFFOLDING, AND EVIDENCE-BASED EXPLANATIONS

\section{Introduction}

Explanation-building is at the heart of making sense of the natural, technological and social world (de Vries, Lund, \& Baker, 2002; Salmon, 1989; Sandoval \& Reiser, 2004). In our work we view explanation-driven inquiry as the means to learn, do and teach science, a view which is supported by extensive literature in science teaching and learning (Anderson, 2002; Chinn \& Malhotra, 2002; Donovan \& Bransford, 2005; NRC, 1996; White \& Frederiksen, 1998). The design of learning environments that nurture the practice of explaining can be very powerful: children's engagement in the process of creating explanations is an epistemic activity that can foster students' knowledge acquisition and help refine existing knowledge structures (de Vries, Lund, \& Baker, 2002; Sandoval \& Reiser, 2004).

In this paper we examine the relationship between cognitive ability grouping, reflective

Deleted: students' scaffolding and the quality of students' collaborative causal explanations of a complex ecological problem. The term general cognitive ability refers to the students' capacity to grasp and learn concepts, understand the relationships of concepts and solve problems. This study was part of a broader research project that aims to investigate software-based scaffolding as a means to support middle-school students' inquiry learning. The study seeks to contribute to current understanding of the complex interplay between software scaffolds and students' collaborative 
inquiry learning in science, by investigating whether the scaffolding provided by inquiry-support systems had a differentiated effect in supporting students of varying cognitive abilities to engage in extended inquiry projects. To our knowledge, the question of whether software-based inquiry scaffolding has differentiated effects on students' collaborative explanation construction according to their cognitive ability has not received much attention in the literature.

The paper begins with an overview of students' difficulties with evidence-based explanations in inquiry-based science learning and a discussion of scaffolding to help students overcome such difficulties. We then present the methodology of a study designed to examine the relationship between grouping and reflective scaffolding. We conclude with a presentation of the results of this study and a discussion of the implications for scaffolding different cognitive ability students' explanation building.

\section{Students' difficulties with scientific reasoning and creating evidence-based explanations}


to encounter difficulties when asked to corroborate their explanations of physical and biological phenomena (Brewer, Chinn, \& Samarapungavan, 2000; Kuhn, et al., 1988; Sandoval, 2003; C. Zimmerman, 2005; Zuzovsky \& Tamir, 1999). It is extremely important to address students' challenges, as it has been shown that formulating explanations can improve one's understanding (Chi, Leeuw, Chiu, \& LaVancher, 1994); furthermore, it has been suggested that articulating explanations, verbally or in writing, is a characteristic of higher-achieving students (Chi, Bassok, Lewis, Reimann, \& Glaser, 1989).

One commonly reported theme is students' difficulties with explanation building. Explanation can be seen as the ultimate goal of scientific inquiry (Salmon, 1989) and, as an extension, a primary goal in learning science. Middle-school students are able to provide explanations of how the world around them works, but may not cite evidence in support of their explanations (Glassner, Weinstock, \& Neuman, 2005; Kuhn, et al., 1988; Wu \& Hsieh, 2006), even in cases when their explanations are warranted by the data they have examined (Sandoval, 2003). When students do cite evidence, there may be problems relating to the quality of this evidence (McNeill \& Krajcik, 2007; Sandoval \& Millwood, 2005). Another area of difficulty is considering alternative explanations of the data (Author; Mynatt, Doherty, \& Tweney, 1977). In previous research with seventh grade students we provided evidence indicating that students' challenges in discussing alternative explanations of their data were related to their epistemologies of what constitutes a good scientific explanation and argued that students can be guided in understanding the role of addressing alternative explanations (Author). 


\section{Reflective inquiry: an essential process in explanation building}

From the discussion thus far, it appears that students need support in understanding what counts as evidence, determining the quality and appropriateness of evidence, and creating persuasive arguments within the domain-specific explanatory framework they are investigating (Sadler, 2004). Some of the challenges students encounter become more apparent when they are engaged in inquiry-based learning, are asked to work collaboratively to solve data-rich problems and construct evidence-based explanations. Reiser (2004) summarized students' challenges as relating to the cognitive complexity and unfamiliar social interaction and discourse patterns, with non reflective work being one of the crucial cognitive challenges. Specifically, Reiser argued that "for learning through investigation to succeed, students must not only construct solutions to the particular scenario but must connect the explanations or arguments they construct to more general disciplinary frameworks" (Reiser, 2004:278). To be successful, learners should approach inquiry reflectively, engaging with each cognitive task mindfully. Adopting a reflective stance to complex inquiry situations is prerequisite to deep understanding (Dewey, 1910) but, at the same time, is not an endeavour that students engage with spontaneously in school science (Loh, 2003). Following Loh (2003) we define reflective inquiry as the process during which students temporarily halt their investigation to monitor and evaluate the process and product of inquiry in order to help them coordinate present action and to plan next steps. Our position is that engaging in inquiry alone is not sufficient to help students overcome known inquiry challenges, but that students need to develop a reflective approach to learning, one that involves systematic examination of inquiry activities (e.g. formulating hypotheses, interpreting and evaluating data, etc.) as they relate to each other and which engages students in planning, monitoring, and evaluating their ongoing investigation (Author). 


\section{Scaffolding students' explanation building}

2

3

4

8

9

An important question of interest for the design of inquiry-oriented learning

environments is whether one could scaffold students in overcoming some of the reflective inquiry challenges they encounter when asked to provide evidence-based explanations for complex problems and the extent to which support for reflective inquiry can have an impact on this effort. "Reflective inquiry scaffolding" refers to those structures that can support the coupling of students' inquiry activities and reflection during students' explanation building process. The term "scaffolding" is used to describe situations when a more knowledgeable person helps the learner progress within their zone of proximal development, reaching the point where assistance is no longer required to perform the initial task. Scaffolding can take place in real time or through pre-planned activities that seek to promote emergent autonomy. We adopt an interpretation in which scaffolding can be seen as a system of interacting agents (Tabak, 2004), which can be human (e.g. teacher, peers) or software-based (e.g. pre-designed prompts, cross-reference anchors, compound activity strategies).

Software-based prompting can be used as a means to help students engage with evidencebased explanation building (Davis, 2003). Engaging students in collaborative processes is another pedagogical strategy for creating opportunities for the articulation of explanations and the coordination of inquiry work and explanation building (Scardamalia \& Bereiter, 1994), as having students collaborate affords the externalization of ideas and the joint creation of understanding between the members of a group. 
1

2

3

4

5

6

7

8

9

Learning technologies have the potential to support students' deep understanding of scientific concepts (Krajcik, 2003). Scaffolded software tools can support learners in overcoming significant obstacles which arise when trying to make sense of complex data; such obstacles are often related to conceptual, epistemic, and metacognitive difficulties. We next provide selective examples to illustrate current understanding of how software scaffolding can support explanation building.

Researchers (Sandoval, 2003;Sandoval \& Reiser, 2004) have argued that software tools $\underline{\text { can serve as epistemic tools to develop students' epistemologies of science. According to }}$

Deleted: This brief review is necessarily a selective discussion of the literature, as explanation building in datarich problem-solving is a complex endeavor.

Deleted: W.A.

Deleted: W. A. Sandoval, 2003;

Sandoval (2003), there is currently little emphasis on supporting students' understanding of the nature of science as they engage in inquiry-based learning; Sandoval suggests that epistemic tools structured around the task of constructing causal explanations can contribute to developing students' epistemologies by providing the disciplinary and epistemic frameworks to situate inquiry and create artifacts that support public discussions of complex constructs.

ExplanationConstructor is an example of an inquiry-support tool which provides conceptual and epistemological guidance for engaging in deep science learning (Sandoval, 1998), and which has been shown to support the development of students' domain-specific explanations (Sandoval, 2003). A main feature of the ExplanationConstructor software is the presence of explanation guides which represent a theoretical framing of the topic under investigation. Another important aspect is the provision of representational features, such as links, to enable the visual connection of data to arguments. These features are used to support students' disciplinary discussions of their data and to make explicit important components of scientific explanations explicit to students. 
Scaffolds have also been employed to help students regulate the inquiry process (de Jong, 2006), as processes such as planning, monitoring, and evaluating developing explanations have also been proven to be a challenge when dealing with data-rich inquiry investigations.

Symphony (Quintana, Eng, Carra, Wu, \& Soloway, 1999) is a tool that supports students in planning and monitoring their work, by providing representations that conceptually scaffold students and guide them in connecting their inquiry steps.

The "Web-Based Inquiry Science Environments" online platform -WISE-(Linn, Clark, \& Slotta, 2003)adopts a an inquiry map and prompts, which offer detailed, step-by-step guidance to focus student work with online sources. Generic prompts asking students to reflect and monitor their ongoing understanding, embedded in WISE have been shown to improve student learning. The Progress Portfolio tool (Loh et al., 2001) enables teachers to design explanation template pages, facilitates students' linking of data as evidence, and uses prompts and articulation boxes to encourage reflection. Both the Progress Portfolio and WISE include scaffolds that facilitate students' organization, articulation and reflection of data.

Our brief review of types of software tools that have been shown to support students' explanation building suggests that learning technologies can play a significant role in structuring students' explanation building and providing the support needed to overcome known inquiry challenges. In the next section, we provide an overview of the contribution of collaborative learning and, within this section, discuss another function of software tools: that of supporting collaborative learning.
Deleted: D

Deleted: Planning

Deleted: and

Deleted: s
Deleted: The Progress Portfolio tool (Loh et al., 2001) enables teachers to design explanation template pages, facilitates students' linking of data as evidence, and uses prompts and articulation boxes to encourage reflection. Deleted:

Deleted: The type of scaffolding has also been reported to influence learning.

Deleted: (Web-Based Inquiry Science Environments) 

1

2

3

4

5

6

7

8

9

\section{Collaborative learning}

Many researchers have argued that, under certain conditions, collaboration improves

learning more than individual learning situations (Bowers, Pharmer, \& Salas, 2000; Johnson \& Johnson, 1989; Johnson, Johnson, \& Stanne, 2000; Slavin, 1990). Furthermore, there is a strong argument in favor of reforming instruction, so that it has the potential to make learning in classrooms more authentic and motivational (NRC, 1996). For example, Blumenfeld et al. (1991) argued that students should be able to participate in learning environments that reflect the complexity of the world around them; ones that have the capacity to motivate them and engage them in higher-order thinking; and ones that are predominantly social.

Dillenbourg, Baker, Blaye and O’ Malley (1996) categorized research on independent $\underline{\text { variables influencing collaborative learning as belonging to the following broad categories: }}$ group composition, features of the task, context of collaboration, and the communication medium. However, Dillenbourg et al. (1996) also claimed that it is almost impossible to investigate the topic of supporting collaboration in a controlled manner, since these variables interact with each other and argue that research should, instead, focus on the process of

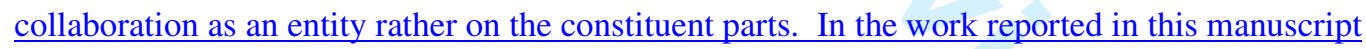
we mainly adopt Dillenbourg's approach, by focusing on the collaborative outcomes of lowachieving students' collaborative learning process. Since academic achievement grouping is a key variable in our study, in this section we discuss existing literature on the effect of two main variables on collaboration: group composition and computer tools as the mediating artifacts.
Deleted: istic
Deleted: One of the reasons for the positive effect of collaboration is the possibility for extended cognitive elaboration and argumentation: working in groups supports giving and receiving explanations, which in turn has been linked to gains in achievement tests $(\mathrm{N}$. M. Webb, 1982). 

would be difficult to isolate all the relationships between all variables that may play a role in deciding the effectiveness of a group effort; however, factors such as individual characteristics, group composition and the nature of the task have been identified as important (Bowers, et al., 2000). Several studies have examined whether the composition of a group influences the outcome of the collaboration, focusing mostly on cognitive gains. The size of a group has been shown to have an effect on achievement, with dyads and small groups mostly preferred during collaborative learning. For instance, dyads are preferred to avoid social loafing and promote individual and collective accountability while small groups are preferred for the potential to create productive, cognitive conflict. Group size has been investigated mostly in non-problem based learning contexts (Fuchs et al., 2000), thus making it problematic to draw conclusions when referring to reformed-based learning environments. While Fuchs et al. (2000) report controversial results from the few studies which carefully manipulated group size, their study findings with complex tasks in mathematics indicated that low-achieving students benefited from working in dyads with a high-achieving student. However, students' interactions were still judged of low quality. Kutnick and Thomas (1990) compared dyads and individual middleschool students' understanding of scientific concepts, while also manipulating the achievement level of each dyad member. Their findings indicate that dyads showed learning gains, as measured by a pre- and post-test, while the scores of students working alone decreased. In a follow-up study, using different subjects, Kutnick and Thomas (1990) manipulated the 
composition of dyads, based on achievement levels, and presented findings showing that students' achievement increased regardless of whether they were placed in homogenous or heterogeneous pairs. However, Kutnick and Thomas (1990) warn that cognitive gains are contingent on task structuring and the meaningfulness of the task.

Studies have provided evidence that middle-achieving students benefit from working in homogenous groups while low-achieving students benefit from participating in heterogeneous groups, while there is no clear conclusion as to what benefits high-achieving students most (Webb, 1982). Bowers, Pharmer, and Salas (2000) performed a meta-analysis of 13 studies, asking whether group homogeneity resulted to greater performance; homogeneity was determined by examining gender, ability level, and personality. Results from this synthesis indicated no statistically significant results related to whether the group was heterogeneous or homogeneous; no significant results were found regarding the impact of any of the three attributes on task performance. The authors concluded that attending to these attributes alone will not improve performance. While some researchers have argued for same-gender groups, based on the argument of different collaboration styles between females and males, others conclude that research on the role of gender in collaborative learning has been inconclusive (Harskamp, Ding, \& Suhre, 2008; O'Donnell, 2006).

Such conclusions lead us to examine the nature of the interactions, as a decisive factor in determining a group's individual and collective learning gains. Other studies also support the claim that the nature of the interaction between the members of the group may, in fact, play a more central role than group heterogeneity. For instance, Cheng, Lam, and Chan (2008) studied 367 groups of secondary school students, collaborating on a project and found that heterogeneity (groups consisting of high and low achieving students), gender, and group size were not 
important factors in students' learning efficacy, which was decided based on the quality of the intra-group interactions. Aspects such as the quality of interactions and the structure of the interaction appear to impact the collaborative process. Giving and receiving explanations has been shown to improve learning (Chi, Leeuw, Chiu, \& LaVancher, 1994). One of the reasons for the positive effect of collaboration is the possibility for extended cognitive elaboration and argumentation: working in groups supports giving and receiving explanations, which in turn has been linked to gains in achievement tests (Webb, 1982).

In Saleh, Lazonder, and de Jong's (2007) study, $4^{\text {th }}$ graders in the experimental condition had continuous access to index cards, containing guidelines about desired collaborative behavior; the researchers found that structuring the collaboration activity and motivating students by using group rewards increased the participating fourth grade students' academic achievement and the collaborative cognitive elaboration activity. Average-ability students appeared to have benefited the most while, despite the increase in performance, low-ability students' verbal interactions were still deemed of low quality. Saleh et al's results underline the need for $\underline{\text { scaffolding different ability students using a variety of instructional strategies. According to }}$ Baker and Lund (1997) computer tools can be designed so that they can provide flexible structuring to collaborative learning, so that certain collaborative interaction patterns can be supported. The area of computer-supported collaborative learning, which is central to the present study, is discussed next.

\subsection{Computer-supported collaborative learning}

It is widely accepted that computer-based tools can mediate human behavior to the extent that they can influence human reasoning processes; several researchers have also argued in favor 
of technology's role in the form of indispensable tools, augmenting what can normally be done with human cognition alone (Hutchins, 1995; Salomon, Perkins, \& Globerson, 1991). The potential of software tools and software scaffolding to support interaction and collaboration around problem solving has also been extensively discussed (Barron, 2000; Clark, Weinberger, Jucks, Spitulnik, \& Wallace, 2003; Kreijns, Kirschner, \& Jochems, 2003; Manlove, Lazonder, \& de Jong, 2006; Soller, Martinez, Jermann, \& Muehlenbrock, 2005; Stahl, Koschmann, \& Suthers, 2006).

Computer supported collaborative learning is not, however, automatically occurring whenever a tool is introduced (Dillenbourg, 2002; Kreijns, et al., 2003). Two main functions of technology in supporting collaborative learning have been identified in the literature as necessary for affording productive collaboration: structuring and regulating collaboration (Dillenbourg, 2002; Jermann, Soller, \& Lesgold, 2007). Jermann, Soller, and Lesgold (2004) presented a classification of technological tools which are specifically designed to support the structuring and regulation of collaboration. Specifically, they identified the following categories of tools: Graphical argumentation tools, structured dialogue interfaces, mirroring tools, metacognitive tools, computer-based coaches and facilitators, and knowledge-building tools.

When a good match between learning goals, the affordances of technology, and instructional support is achieved, computer-supported collaboration can contribute to higherorder cognitive activities, such as argumentation, explanation, critical thinking and inquiry of complex problems (Järvelä, Häkkinen, Arvaja, \& Leinonen, 2004; Linn, 2003). Collaborating with peers also raises additional challenges, such as building common ground and coordination. Scaffolded software tools, such as Belvedere (Suthers \& Jones, 1997; Suthers \& Weiner, 1995), ExplanationConstructor (Sandoval, 2003), WISE (Linn, et al., 2003), Symphony (Quintana, et 
al., 1999), and the Progress Portfolio (Loh, et al., 2001) are just a few examples of tools which were designed specifically to provide technological support for collaborative explanation building. For instance, Belvedere (Suthers \& Jones, 1997; Suthers \& Weiner, 1995) is a tool developed to support the collaborative externalization of developing relationships between hypotheses and data. According to Suthers (2001), representational guidance tools allow the Deleted: public construction of knowledge, guided by the existing representational features, which can facilitate or constrain understanding. Suthers (2001) hypothesized that when these representations are used for deep understanding they become the basis for coordinating Deleted: Deleted: collaborative work. In a study examining the relationship between representational guidance and ninth grade students' inquiry skills, Toth, Suthers, and Lesgold (2002) found that the combination of representational guidance, provided by the Belvedere evidence mapping tools, and explicit reflection structures resulted to significantly better evidence-based reasoning than the non-scaffolded condition.

\section{Study goals}

It has been argued that, beyond the analysis of individual cognitive activity, we also need analyses of the process and products at the level of the collaborating group (Stahl, et al., 2006). Hence, this study takes the pair as the unit of analysis. In a qualitative study of three pairs of $7^{\text {th }}$ grade students of high, middle, and low academic achievement, we found that even though the scaffolding created more opportunities for pairs of students to discuss their interpretations of the data, the quality of their conversations appeared to be related to their characterized academic achievement (Author). For example, it was observed that the lower-achievement students' 
explanations were less extensive and more superficial as compared to those of the higher-

achievement students. Reports in the literature also indicate that lower- achieving students need more support than higher achieving students in order to successfully engage in the same tasks (B. J. Zimmerman, 2002; C. Zimmerman, 2000) even though it has been argued that both high- and low-achieving pairs need to be scaffolded in order to engage in higher order thinking (Cohen, 1994).

In the work presented in this paper we investigated whether the provision of computerbased scaffolding could support low-achieving pairs in creating evidence-based explanations. The current study was guided by the following main research questions: a)_What was the nature of students' collaborative explanations of a complex inquiry problem? Specifically, to what extent did the pairs create valid and evidence-based explanations? To what extent did they attend to and provide evidence arguing against alternative accounts of their data? b) Furthermore, what was the relationship between the pairs' cognitive ability, reflective scaffolding, and the pairs' explanations?

\section{Methodology}

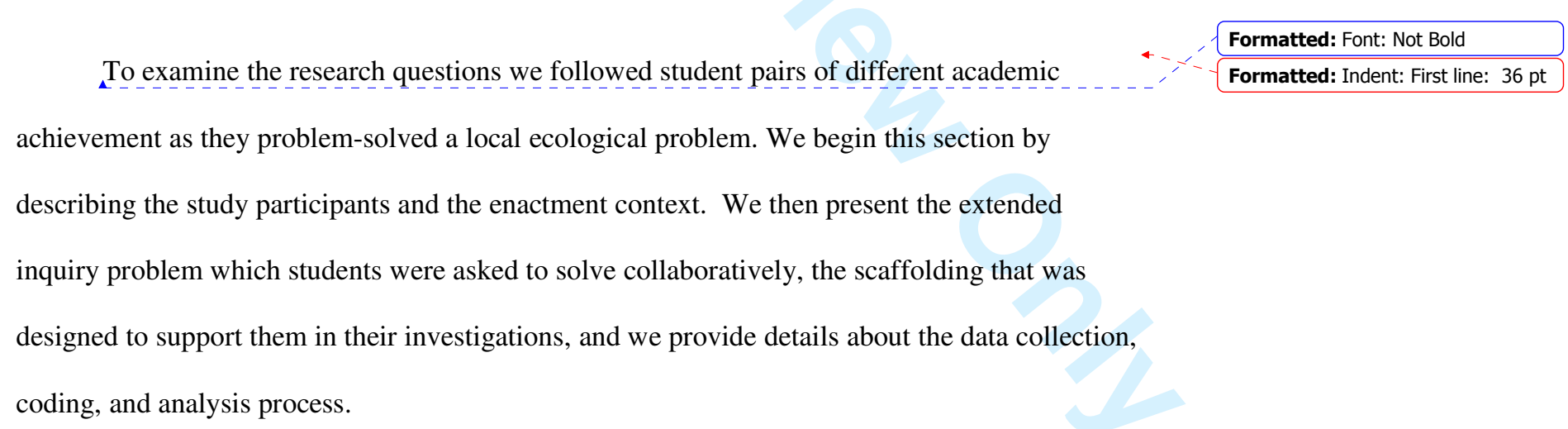




\subsection{Participants}

Formatted: Indent: First line: $36 \mathrm{pt}$

Fifty-three students from two intact sixth grade classes $(n=26, n=27)$ of a suburban state

$\mid$ school in Cyprus participated in this study. Both classes used the inquiry environment of the STOCHASMOS web-based platform, which is described in the next sections, to access multimodal inquiry data. To study the effects of two different types of scaffolding on students' inquiry each class was assigned to one of two learning situations: the students in one of the classes used the STOCHASMOS inquiry environment and Microsoft PowerPoint (“PPT"), while the students in the other class used the STOCHASMOS inquiry environment and the scaffolded web-based WorkSpace of STOCHASMOS ("WorkSpace”) to organize their inquiry data and create their written explanations. Both classes were taught by the same science teacher, who had sixteen years of teaching experience and a master's degree in science education. It was the first time the teacher was teaching an extended software-based inquiry investigation.

Instruction was designed to be comparable across classes. This was achieved by frequent meetings with the teacher, before and after each class session, to minimize divergences in approach. To assess the similarity of instruction in the two classes, we compared the number and duration of sessions for each class, the tasks students worked on during each session, and the whole-class teacher interventions. As indicated by the videotapes and researcher field notes, the teacher kept the instruction as similar as possible in terms of duration, emphases, and opportunities for feedback in both classes. The students had not participated in any other extended inquiry-based science projects during the school year and had not been taught any other ecosystem topics up to that time in the year. Based on their teachers' reports and the national 
curriculum framework, it was assumed that all students were briefly taught about food chains back in $3^{\text {rd }}$ grade.

\subsection{The inquiry environment}

Students in both classes worked with the Flamingo inquiry investigation, which was hosted on STOCHASMOS, a web-based platform for inquiry teaching and learning. The students had access to complex data relating to an authentic environmental science problem about the sudden death of a large number of flamingo birds at the Larnaca Salt Lake (Hadjichristoforou, 2004). To successfully solve the problem and present a persuasive explanation, students were expected to create and communicate a causal explanation detailing how the changing relationships between the abiotic and biotic factors in the salt lake ecosystem resulted in the death of the flamingos. The successful solution of the problem required the understanding that the heavy rainfall in 2003 increased the water level more than any other year in recent decades, and this led to a decrease in the lake's salinity. The fluctuations of salinity regulate the birth and hatching of Artemia Salina, a shrimp on which the Flamingo feed. Artemia Salina gives birth to cysts, which will only hatch above a certain salinity level. This chain of events led to a reduction in food levels for the flamingos, while at the same time the increased rainfall made the nearby rifle shooting range area accessible to the birds, who wandered there looking for food. In order for students to further understand why the flamingos died of lead poisoning, they needed to examine the interdependencies within the ecosystem as well as understand the birds' filter feeding behavior and the impact that external factors had on it. 


\subsection{The enactment context}

Prior to the Flamingo investigation, the two classes completed a different, three-day investigation hosted on STOCHASMOS to get acquainted with the inquiry environment section of the platform. They then engaged with the Flamingo investigation, which took place during six weekly 80-minute sessions. Students in both classes were asked by the teacher to record their hypotheses, gather data in support of their ideas, and write a final report addressed to the Fisheries Department explaining why the flamingo died. The students worked in pairs ${ }^{1}$ with the goal of synthesizing and presenting a persuasive explanation. The teacher defined a persuasive explanation as one that included a claim, the reasoning behind the claim, and was substantiated by data selected from the investigation environment and analyzed. To increase explanatory power, the explanation ought to refute alternative explanations, by explaining the reasoning behind the refutation, and providing, wherever possible, evidence supporting this refutation.

Such a framework, that includes explicit references to the components of an explanation, explains the reasoning behind refuting alternative explanations and provides evidence for it, has been discussed in the literature as having the potential to foster the development of scientific reasoning skills (McNeill, Lizotte, Krajcik, \& Marx, 2006; Sadler, 2004).

\subsection{Software tools used in each of the learning situations}

\section{Students in both classes used the STOCHASMOS web-based inquiry environment to}

access inquiry data and background information about the Flamingo investigation. The students

${ }^{1}$ All students worked in pairs, with one exception in which students worked in a triad, due to the total number of students in the class. For brevity, we will use the word "pairs" for all student groups. 

1

in one of the $6^{\text {th }}$ grade classes used the STOCHASMOS inquiry environment and the STOCHASMOS WorkSpace to organize their data and document their explanation, whereas the students in the other class used the STOCHASMOS inquiry environment and Microsoft PowerPoint. STOCHASMOS is a scaffolded software platform which builds upon prior design and research efforts, such as enabling students to easily query databases (Tabak, Sandoval,

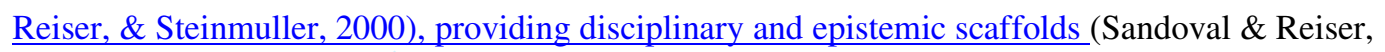
2004), providing tools for organizing data and articulating thoughts (Loh et al., 1997; Sandoval \& Reiser, 2004), and facilitating the design of web-based scaffolded inquiry environments (Linn, Davis, \& Bell, 2004). The design of STOCHASMOS reflects a combination of features seeking to scaffold collaborative sense-making, process management, and articulation and reflection (Quintana, et al., 2004), to support students' inquiry process and explanation building. The STOCHASMOS platform was purposefully built to facilitate students' reflective inquiry and support the researchers' examination of students' inquiry practices. As such, one of the main components of STOCHASMOS, the reflective WorkSpace, can be de-activated selectively, so that one can create research designs in which the use of the tool can be investigated with or without certain components. Following this logic, one of the classes in this study was provided access to the STOCHASMOS inquiry environment only, whereas the other class was provided access to the STOCHASMOS inquiry environment and the STOCHASMOS reflective inquiry WorkSpace. We next provide more details about the commonalities and differences between the tools used in each of the classes

\subsubsection{STOCHASMOS components common to both classes: Inquiry environment}

The inquiry environment was one of the core STOCHASMOS components that was made available to both classes. Students used the web-based inquiry environment to access

Deleted: No explanation-building scaffolding was provided in the STOCHASMOS inquiry environment whereas such scaffolding was purposefully designed in the STOCHASMOS WorkSpace. Deleted: II II

Formatted: Heading 3

Deleted: STOCHASMOS

Deleted: a 
multimodal data about the Flamingo investigation. The scaffolding tools available in the

$\underline{\text { STOCHASMOS inquiry environment are described in Table } 1 .}$

\section{Table 1. STOCHASMOS Inquiry Environment Tools}

\begin{tabular}{|c|c|}
\hline Feature & Function \\
\hline Tabbed interface & $\begin{array}{l}\text { The designer of the learning environment presents the data } \\
\text { through a tabbed interface. Tabs segment the information into } \\
\text { meaningful chunks. Data are presented in text, images, video, } \\
\text { or sound formats. Within each tab data can also be arranged in } \\
\text { separate pages, which are shown as a list menu within each } \\
\text { page. Within each page the designer can also embed a graph } \\
\text { generation tool, which is used to access a database of relevant } \\
\text { information. The first tab is titled "My Role", and includes the } \\
\text { driving question of the problem the students are asked to } \\
\text { solve. }\end{array}$ \\
\hline Glossary & $\begin{array}{l}\text { This tool is used to allow students to gain easy access to } \\
\text { customized definitions of difficult terminology. Words that } \\
\text { have a glossary entry are shown in green color and are } \\
\text { underlined. Upon mouse over, a pop-up window opens and } \\
\text { displays the definition of the word. The glossary is } \\
\text { customizable for each learning environment. }\end{array}$ \\
\hline Graph Tool & $\begin{array}{l}\text { The Graph tool enables students to run comparisons of } \\
\text { numeric data, based on variables which are pre-defined by the } \\
\text { designer. It can display data as bar or line charts. }\end{array}$ \\
\hline$\underline{\text { Hints }}$ & $\begin{array}{l}\text { Hints can provide more help or explanation regarding the work } \\
\text { that students are expected to do. They are customizable at the } \\
\text { designer's level and are unique for each learning environment. }\end{array}$ \\
\hline
\end{tabular}

To facilitate process management and focus the learners' attention on the sense making (2004) as providing tools to "automatically handle nonsalient routine tasks". According to this strategy, certain micro-tasks such as graphing data in the process of solving a more complex problem, may distract some novice learners and increase their cognitive load. Providing tools to automatically create graphs can focus the learner's cognitive resources on the conceptual issues of which graphs to generate and how to interpret them (Reiser et al., 2001). Following these

\section{Formatted Table}

\section{Deleted: $\mathscr{T}$}

Deleted: Students in both classes used the STOCHASMOS web-based inquiry environment to access inquiry data and background information about the Flamingo investigation. The students in one of the $6^{\text {th }}$ grade classes used the STOCHASMOS inquiry environment and the STOCHASMOS WorkSpace to organize their data and document their explanation, whereas the students in the other class used the STOCHASMOS inquiry environment and Microsoft PowerPoint. No explanation-building scaffolding was provided in the

STOCHASMOS inquiry environment whereas such scaffolding was purposefully designed in the STOCHASMOS WorkSpace. STOCHASMOS was selected as a platform to investigate the designers intent to support inquiry-based learning and evidence-based explanation building, whereas PowerPoint was selected

because of the students' familiarity with it as a medium to present their ideas. We next provide descriptions of these two tools, describing in more detail the less familiar tool, STOCHASMOS.II II 6.4.1 The STOCHASMOS learning platformII

STOCHASMOS is a scaffolded software platform which builds upon prior design and research efforts, such as enabling students to easily query databases

(Tabak, Sandoval, Reiser, \& Steinmuller, 2000), providing tools for organizing data and articulating thoughts (Loh et al., 1997; Sandoval \& Reiser, 2004), and facilitating the design of web-based scaffolded inquiry environments (Linn, Davis, \& Bell, 2004). The design of STOCHASMOS reflects a combination of features seeking to scaffold collaborative sense-making, process management, and articulation and reflection (Quintana, et al., 2004), to support students' inquiry process and explanation building. II

6.4.1.1 Scaffolding sense-making and process management $t$

Deleted: B. J 
guidelines, we designed a graph generation tool embedded within the inquiry environment, to support students' conceptual engagement with the data. The intent behind the software-based scaffolding was to support students in engaging in scientific inquiry largely independently and to minimize the need to continually refer to the teacher for tasks they could accomplish on their own.

This type of scaffolding was complemented by other teacher and task-related scaffolding, as different types of mechanisms need to co-exist and work in synergy, in order to successfully support learning in complex, classroom-based learning situations (Tabak, 2004). For instance, to facilitate students' investigation processes the teacher asked all students in both classes to begin their work by writing down three hypotheses and then select one of them as a starting point. Such teacher-controlled scaffolds were discussed with the teacher ahead of class, in the course of preparatory meetings, and were implemented with all participating students.

\subsubsection{The STOCHASMOS Reflective WorkSpace environment}

STOCHASMOS includes a separate component, the reflective WorkSpace, where students can document and organize data from the STOCHASMOS inquiry environment and provide written articulations of their explanations. The WorkSpace can be activated or deactivated by the designer of the learning environment. For this study, the WorkSpace area was de-activated for the students in the PowerPoint class. The WorkSpace provided students with scaffolding to help them organize their inquiry-related data and articulate their thinking, Figure 1 illustrates the scaffolds which are available in the STOCHASMOS reflective WorkSpace, while Table 2 explains their function.

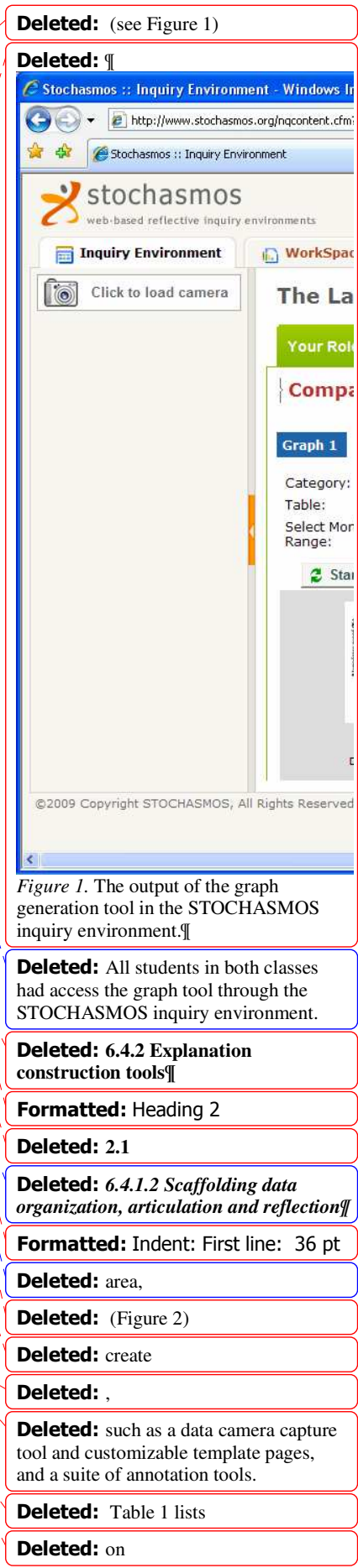


Figure 1, The explanation building scaffolding in the STOCHASMOS WorkSpace

\section{Table 2. STOCHASMOS Reflective WorkSpace Scaffolding}

\begin{tabular}{|c|c|}
\hline WorkSpace Feature & $8+2$ \\
\hline Data Camera Capture Tool & $\begin{array}{l}\text { This tool is present in the Inquiry and the WorkSpace } \\
\text { environments. Clicking on it while in the Inquiry environment } \\
\text { allows students to specify and capture an area on their screen, } \\
\text { which includes data to support their arguments. After } \\
\text { selecting the "capture image" button on the Data Camera } \\
\text { Capture Tool, the image of the data is automatically stored and } \\
\text { can be retrieved from the Image Browser section in the } \\
\text { Reflective WorkSpace. }\end{array}$ \\
\hline Image Browser & $\begin{array}{l}\text { The Image Browser tool facilitates access to captured data, } \\
\text { which are represented as thumbnails. Students can browse all } \\
\text { the data they have captured and can drag and drop selected } \\
\text { data into data boxes, which reside in pages created from } \\
\text { templates. }\end{array}$ \\
\hline $\begin{array}{l}\text { Annotation and } \\
\text { Organization Tools }\end{array}$ & $\begin{array}{l}\text { A suite of tools is available to allow students to annotate their } \\
\text { data and articulations, stored in pages created from templates. } \\
\text { The following annotation and organization tools were } \\
\text { available in the current version of the Reflective WorkSpace: } \\
\text { Insert Text Box, Insert Image Box, Insert Arrows, Insert Data } \\
\text { link Box, Delete. }\end{array}$ \\
\hline
\end{tabular}




\begin{tabular}{|c|c|}
\hline WorkSpace Feature & Function \\
\hline Templates & $\begin{array}{l}\text { Students use templates, accessible from the Reflective } \\
\text { WorkSpace, to create their own pages. Templates are pre- } \\
\text { designed and are unique to each learning environment. Once } \\
\text { the students select a template, they name it according to its } \\
\text { role (e.g. environment). Once created, the page then appears } \\
\text { in the WorkSpace. Templates can include Articulation spaces, } \\
\text { Data organization spaces, and Data Link Boxes. }\end{array}$ \\
\hline Articulation Boxes & $\begin{array}{l}\text { Students use Articulation Boxes to record written } \\
\text { interpretations and explanations of the data. }\end{array}$ \\
\hline Data Boxes & $\begin{array}{l}\text { Students use Data Boxes to drag and drop data as evidence } \\
\text { from the Image Browser tool. }\end{array}$ \\
\hline$\underline{\text { Data Link box }}$ & $\begin{array}{l}\text { This tool is used to link to other WorkSpace pages which } \\
\text { students created. Linking to other pages facilitates evidence- } \\
\text { based explanations. }\end{array}$ \\
\hline
\end{tabular}

As students work with the investigation in the STOCHASMOS inquiry environment, they can select data to support their hypotheses by using the data camera capture tool. The system, then, automatically stores images of these data in the WorkSpace area from where students can retrieve, organize and interpret them. In this study, we used three template pages to guide their inquiry learning: the hypothesis template page, the data page template, and the explanation template page. The hypothesis template page was intended to support students' in articulating multiple hypotheses about the data. The data page template, was designed to ground students' articulations in the data, by providing space for organizing the captured data, and articulation spaces where students can record their interpretations of the data, thus serving to keep the presentation and interpretation of the data distinct. Finally, the explanation page template (Figure 2) was intended to serve as a synthesis space, where the groups could provide an explanation narrative, and link evidence, already organized in data pages, to support their explanations. 


Deleted: 3
Deleted: $\mathbb{I I}$
Deleted: 2.2

\subsubsection{PowerPoint}

The students in the second class used the STOCHASMOS inquiry environment to access inquiry data and PowerPoint to help them document their explanation. PowerPoint was selected because it was a tool students often used and because we needed a recording medium to document students' explanations so that they could be compared to the WorkSpace class. Students were not provided with written prompts, but were asked by the teacher to use PowerPoint to record hypotheses, organize data from the inquiry environment, and write an evidence-based explanation. Figure 3 shows a student-produced PowerPoint slide to indicate how one pair of students structured their work with PowerPoint; this example is typical of other pairs' work, as well.
Deleted: 6.4.2 The PowerPoint class $\mathbb{T}$ Deleted: es

Formatted: Indent: First line: 36 pt Deleted: one Deleted: of the

Deleted: organize 
Figure 3. An example of a pair's explanation in PowerPoint (translated from Greek)

In summary, the students in the two learning contexts (Workspace and PowerPoint class)

\section{employed different tools to record an evidence-based explanation, as requested by the teacher.}

Only the Workspace class had access to templates which included static prompts guiding students to interpret and document their ideas. All other STOCHASMOS inquiry environment scaffolding tools were accessible to both classes. The template pages and the prompts they included, in effect provided one of the two classes with a sequence of activities that guided the explanation building process. This sequence was not available to the other class. Instead, this class was given specifications from the onset of the unit, which required that their explanations should include hypotheses, data and the reasoning that connects the data to the hypotheses.
Deleted: received differentiated scaffolding

Deleted: with respect to the template pages that were designed to offer structured guidance for explanation building

Deleted: these 
We collected a variety of qualitative and quantitative data for each class, including pre-

and post-test responses, data from students' explanation building process, researchers' field notes, and each of the 26 pairs' work on the computer.

In order to assess the participants' cognitive ability, we administered two ad-hoc measures: the Raven's Standard Progressive Matrices (RSPM), as a general measure of nonverbal intelligence, and a test that measured the participants' understanding of ecosystems (SUE). Raven's Standard Progressive Matrices is a paper-and-pencil, multiple-choice and culture-fair test widely used as a measure of general learning capacity. RSPM consisted of sixty progressive difficulty items and is thought to assess abstract reasoning ability (Raven, Raven, and Court, 1998). Webb \& Treagust (2006) have presented an extensive review arguing in favor of the use of the Raven's test to assess “educative ability or fluid intelligence” (Webb \& Treagust, 2006) in several contexts.

Each student also took an individual pre-test and post-test on students' understanding of ecosystems (SUE), asking students to construct a concept map, representing their ecosystem understanding prior to and after the enactment. It has been widely argued in the literature that concept maps can provide a graphical representation of people's knowledge on a given subject (Cañas et al., 2003; Yin, Vanides, Ruiz-Primo, Ayala, \& Shavelson, 2005). For the SUE task, students were presented with an example concept map from an unrelated content which dealt with animals on a farm, and were asked to use a list of concepts and verbs (or add their own) to create a concept map describing the salt lake ecosystem. This list included concepts and verbs relevant to the ecosystem as well as non-relevant items. This method can be seen as an openended task and has been described as an accurate approach to identifying students' mental 
1

2

3

4

5

6

7

8

9

10

representations (Ruiz-Primo, Schultz, Li, \& Shavelson, 2001). Students' conceptual understanding was scored using an expert criterion map as a reference, representing important relationships between biotic and abiotic factors in the ecosystem (Figure 4). Using a scoring system reported in the literature (Yin, et al., 2005) for each student map we counted the number

of appropriate concepts and the number of appropriate relationships between concepts. Interrater reliability was conducted by the first author and a graduate research assistant using $30 \%$ of the tests. Reliability was estimated at $88 \%$, with all disagreements resolved after discussion between the two coders. Following this, the first author coded the remaining tests.

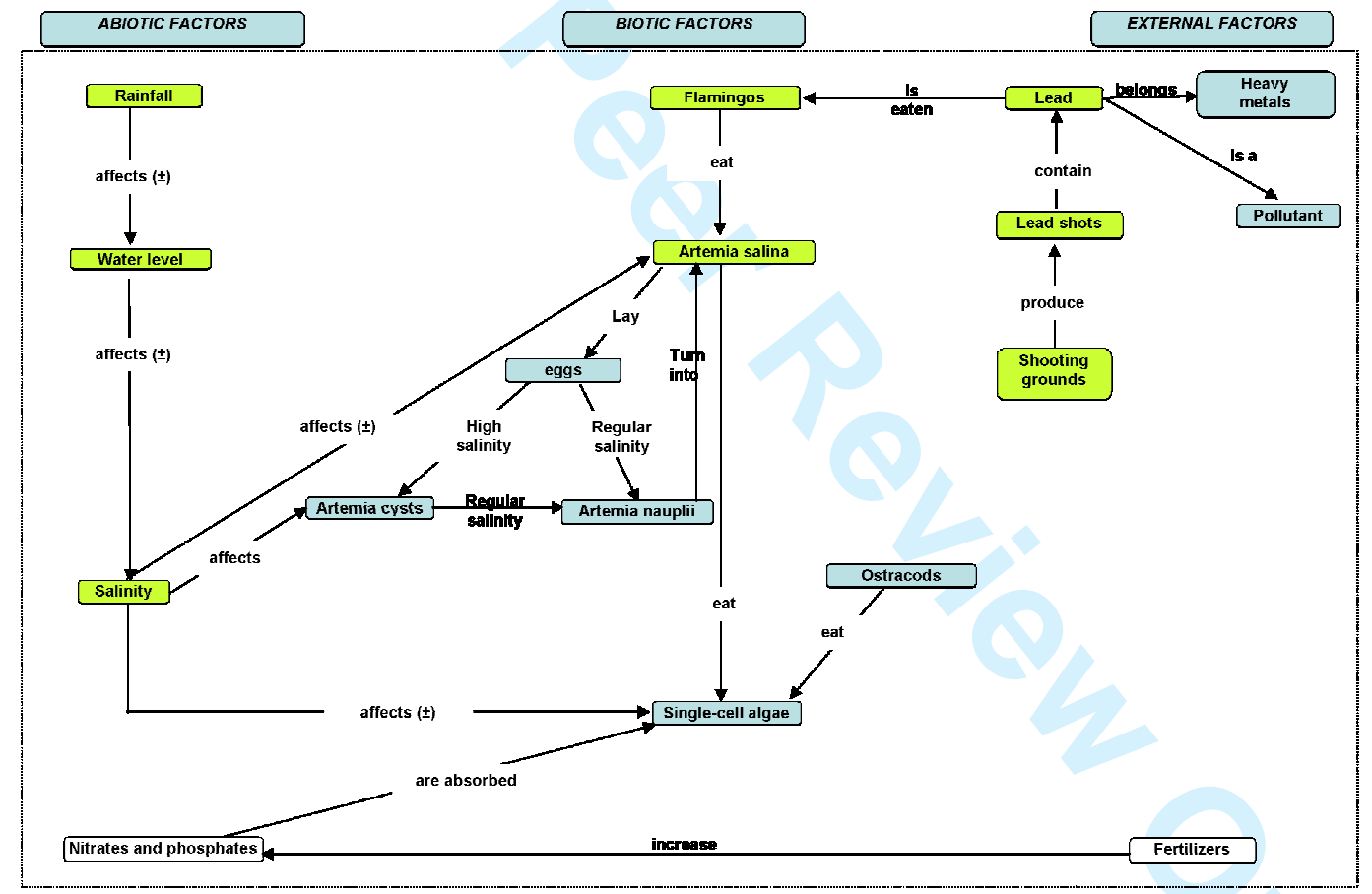

Deleted: 5

Figure 4. The expert criterion map about the Flamingo death problem at the Larnaca salt lake 
Because we had two conditions (WorkSpace class, PowerPoint class), we tested for the initial equivalency of the classes. A two-step cluster analysis was performed to identify natural groupings of children's cognitive ability by using RSPM and SUE as grouping variables. RSPM and SUE were converted into z-scores, to avoid unequal weighting of the variables due to their differing scales. The two-step cluster analysis is an exploratory statistical technique which, based on a number of grouping variables can automatically select the number of clusters so that examinees within a group are similar. The analysis showed that the participants could be grouped in two clusters, one of low learning capacity $(\mathrm{M}=1.43)$ and one of high capacity $(\mathrm{M}=4.33)$. Students in the high learning capacity cluster had higher scores on both the RSPM and SUE variables. The first cluster consisted of 29 students (55\%), and the second cluster consisted of 24 students $(45 \%)$. Each class was comprised of both clusters. A chi-square test indicated that the students in the two classes were equivalent with respect to their learning capacity $\left[\chi^{2}(1)\right.$ $=.46, \mathrm{p}>.05]$. Two t-test analyses with RSPM and SUE as dependent variables and class as independent variable also demonstrated the equivalency of the classes $[\mathrm{t}(51)=-.58, \mathrm{p}>.05$, and $\mathrm{t}(51)=-.14, \mathrm{p}>.05$, respectively].

Since we wanted to examine how the learning capacity may have interacted with the reflective scaffolding condition, the participants in each class were grouped in pairs of three cognitive ability categories, using the results of the cluster analysis: high-high $(\mathrm{HH})$, high-low (HL), low-low (LL). In grouping the students we also consulted with their teachers to form groups who had the potential of collaborating well. There is ample empirical evidence for a strong association between cognitive ability, as it is measured through standardized intelligence tests, and scholastic performance (Deary, Strand, Smith, \& Fernandes, 2007; Jensen, 1998; Rohde \& Thompson, 2007). Measures of general cognitive ability are frequently utilized in the 

1

psychological literature as means of measuring school learning capacity. Moreover having in mind that scholastic performance reflects scholastic aptitude, one can expect the existence of a relationship between scholastic aptitude and individual differences in scholastic learning capacity and understanding. Thus, the methodological manipulation of students with different cognitive ability, may allow a deeper understanding of the interaction between educational and

psychological prerequisites of explanation building. Table 3 shows the number of pairs in each cognitive ability category and scaffolding condition. A Kruskal-Wallis test indicated that the three groups performed significantly different on RSPM and SUE $\left[\chi^{2}(2)=45.1, \mathrm{p}<.05\right.$ and $\chi^{2}(2)$ $=6.22, \mathrm{p}<.05]$ respectively.

Table 3. Pairs in each cognitive ability category and scaffolding condition

\begin{tabular}{|r|c|c|c|c|}
\hline & $\begin{array}{c}\text { Number of Pairs in each Reflective } \\
\text { Scaffolding condition }\end{array}$ & \multicolumn{2}{|c|}{ Mean Ranks } \\
\hline $\begin{array}{c}\text { Cognitive ability } \\
\text { grouping }\end{array}$ & PowerPoint & WorkSpace & RSPM & SUE \\
\hline High-High (HH, High) & 4 & 5 & 44.08 & 32.97 \\
\hline High-Low (HL, Mixed) & 5 & 5 & 25.88 & 27.22 \\
\hline Low-Low (LL, Low) & 4 & 3 & 8.0 & 19.53 \\
\hline Total & 13 & 13 & & \\
\hline
\end{tabular}

The relationships represented in the expert criterion map were also used to decide the correctness of the mechanism-based rationale put forth in each pair's explanation and the quality of the students' explanations. Each pair's final explanation, taken from the PowerPoint files and from the STOCHASMOS WorkSpace was coded using a modified version of Toulmin's (1958) argumentation model. The explanation coding scheme is shown in the appendix. Each explanation was coded for the main explanation provided about why the flamingo died and for 
the students' refuted rival explanations. The main explanation was coded for a) the existence of a claim (Levels 0-2), b) the mechanism-based rationale explaining the claim (Levels 0-5), and c) evidence in support of the claim (Levels 0-4). Similarly, each of the refuted rival explanations was coded for a) the inclusion of refuted claims (Levels $0-1$ ), b) the existence of a rationale as to why the claims were refuted (Levels 0-3), and c) the citation of evidence to support the refutation of the rival explanations (Levels 0-4).

The reasoning levels in the coding scheme represent a progression in students' understanding of the content. The level attributed to each explanation was used to obtain an explanation score. Scores for each explanation component were added to obtain a total explanation score for each pair. The maximum possible total score for an explanation was 19 points: 11 points for the Main Explanation score, and 8 points for the Refuted Rival Explanations score. All twenty-six explanations were coded by a graduate research associate. Inter-rater reliability was obtained with the help of a biology teacher, who scored $15 \%$ of the total number of explanations. The inter-rater agreement was $79 \%$ and the disagreements were discussed and resolved between the coders. The remaining explanations were coded by the graduate researcher on the basis of the discussions with the biology teacher.

\section{Results}

This study was designed to examine the role of reflective scaffolding in supporting students

Formatted: Indent: First line: 21.3 pt of different cognitive ability grouping in constructing explanations during an inquiry-based investigation. Two questions were asked: 1) What was the nature of students' collaborative explanations? 2) What was the relationship between the pairs' cognitive ability grouping, reflective scaffolding, and the collaborative final explanations? The findings' section is 
organized around these questions, after a brief discussion on the effectiveness of the intervention based on the results of the pre- and post-tests.

All pairs, in both classes, constructed explanations describing the reasons the Flamingo died. To assess students' learning gains, and examine the effectiveness of the intervention, we compared their pre- and post-tests using the Wilcoxon signed ranks test. The analysis indicated a statistically significant difference for both the WorkSpace class, $z(26)=-3.60, p<.01$, and for the PowerPoint class, $\mathrm{z}(25)=-2.39, \mathrm{p}=.012$. These results validate the pedagogical intervention, as one that can support meaningful learning about ecosystems.

\subsection{The nature of students' collaborative explanations}

To answer the main research questions, we focused on the analysis of the pairs' collaborative final explanations, as documented in their written artifacts in the STOCHASMOS WorkSpace and in PowerPoint. All pairs in the WorkSpace class and the pairs in the PowerPoint class provided claims explained the reasoning behind their claims. Examining the component of the explanations by using a Mann-Whitney U test, we found differences between the two conditions only on the refuted explanations students provided $[\mathrm{U}(13,13)=39.5, \mathrm{p}=.02]$. Table 4 presents the descriptive statistics for the groups' explanations in the PPT and WorkSpace class.

Table 4. Descriptive statistics for the PPT and WorkSpace classes

\begin{tabular}{lclcccc}
\hline $\begin{array}{l}\text { Type of } \\
\text { scaffolding }\end{array}$ & $\begin{array}{l}\text { \# of } \\
\text { Groups }\end{array}$ & Explanation component & $\begin{array}{c}\text { Mean } \\
\text { score }\end{array}$ & $\begin{array}{c}\text { Std. } \\
\text { Deviation }\end{array}$ & Min. & Max. \\
\hline WorkSpace & 13 & Total Explanation & 11.2 & 3.8 & 6 & 16 \\
& 13 & Main explanation & 6.6 & 1.9 & 3 & 9 \\
& 13 & Refuted Rival Explanations & 4.6 & 2.2 & 0 & 7 \\
\hline PPT & 13 & Total Explanation & 8.2 & 4.2 & 4 & 16 \\
& 13 & Main explanation & 5.5 & 2.2 & 2 & 9 \\
& 13 & Refuted Rival Explanations & 2.7 & 2.6 & 0 & 7 \\
\hline
\end{tabular}


As Table 4 shows, the mean total explanation score for the WorkSpace pairs was higher $(M=11.2)$ than the PowerPoint pairs' $(M=8.23)$. The analysis of the data in Table 4 using the Mann-Whitney $U$ test showed that the mean score for the WorkSpace condition was marginally higher than that of the PowerPoint condition $[\mathrm{U}(13,13)=48, \mathrm{p}=.06]$. In the following sections, we present findings on the similarities and differences observed across conditions and between cognitive ability grouping.

\subsubsection{Students' use of evidence in support of the main explanation claim and reasoning}

The evidence provided by eight of the thirteen pairs in the WorkSpace class and five of the thirteen pairs in the PowerPoint class was characterized as appropriate, with no contradictory or irrelevant information included, thus being labelled Level 3. Table 5 shows the scoring of the evidence provided by the pairs in each class. 
Table 5. Levels of evidence present in the students' main explanations

\begin{tabular}{|c|c|c|c|c|}
\hline $\begin{array}{c}\text { Level of } \\
\text { evidence }\end{array}$ & \multicolumn{2}{|c|}{$\begin{array}{c}\text { WorkSpace } \\
\text { (n=13 pairs) }\end{array}$} & \multicolumn{2}{c|}{$\begin{array}{c}\text { PowerPoint } \\
\text { (n=13 pairs) }\end{array}$} \\
\hline & \# of pairs & $\%$ & \# of pairs & $\%$ \\
\hline L4 & 0 & 0 & 0 & 0 \\
\hline L3 & 8 & 62 & 5 & 38 \\
\hline L2 & 2 & 15 & 1 & 8 \\
\hline L1 & 1 & 8 & 2 & 15 \\
\hline L0 & 2 & 15 & 5 & 38 \\
\hline
\end{tabular}

L4: All evidence is sufficient and appropriate.

L3: No contradictory or irrelevant evidence cited. However, the evidence is not sufficient.

L2: Some evidence provided, but not sufficient. Some of it is contradictory and/or false.

L1: Evidence is provided but all evidence is inappropriate.

As indicated in Table 5 , the majority of the WorkSpace pairs (62\%) provided evidence

scored as belonging to Level 3, indicating an adequate evidence basis to support a causal claim, without any inappropriate, contradictory, or irrelevant evidence included. The respective percentage for the PowerPoint class was $38 \%$. This suggests a difference between the two scaffolding conditions. When examining the same results according to the pairs' learning capacity grouping, we found that none of the four homogenous low cognitive ability pairs in the PowerPoint class provided evidence, whereas only one of the three homogenous low cognitive ability pairs in the WorkSpace class did not provide evidence in support of their claim. At the same time, the observation that no pair attained a Level 4 evidence basis suggests that all students had difficulties with baseline comparisons.

\subsubsection{Students' attention to refuted explanations of the data}

In another study, we provided evidence that $7^{\text {th }}$ grade student pairs, regardless of academic ability level, may not, on their own, consider alternative explanations of their data as 
important to thoroughly research or communicate (Author). In this work, we argued that students' epistemologies guided their inquiry processes and shaped their written explanations.

Throughout the Flamingo investigation, the teacher emphasized that students' explanations ought to be persuasive and that each pair should provide evidence for both their main claim and for explanations they had rejected on the basis of evidence. The STOCHASMOS WorkSpace explanation template also included explicit structures as reminders to also consider alternative explanations they had refuted and the evidence to support their refutations. Hence, in our analysis of the data we also focused on students' refuted explanations, and how the scaffolding provided may have supported the students' written explanations.

Our analyses indicated that 21 of the 26 pairs from both classes provided claims they believed were plausible but not correct as rival explanations. The examination of the rival explanation claims listed, indicated that $92 \%$ of the WorkSpace pairs ( $\mathrm{n}=12$ of 13) listed explanations they had refuted, in contrast to $69 \%$ of the PowerPoint pairs ( $\mathrm{n}=9$ of 13 ). One mixed cognitive ability pair in each class did not list any refuted explanations. In the PowerPoint class there was also one high and three low cognitive ability pairs who did not list alternative explanations.

There were differences between the classes in the number of pairs providing reasoning and citing evidence in support of the refuted explanations of the data. Forty-six percent of the PowerPoint pairs stated their reasoning for refuting alternative explanations of their data and cited evidence in support of listed refuted alternative explanations. On the other hand, the percentage of pairs in the WorkSpace class providing reasoning for refuting alternative explanations was much higher $(92 \%, 12$ of the 13 pairs), with $77 \%$ of these pairs ( $n=10$ of the 13 pairs) also providing evidence to support their rejection of the refuted explanations. 
1

2

3

4

5

6

7

8

9

Communicating and attempting to discount alternative explanations of the data are cognitive behaviours that shape students' practical epistemologies of scientific explanations (Sandoval, 2005) and which one would like to encourage with middle school students. Even though many students in our study were able to list alternative explanations of their data and provide evidence in support of their ideas, an examination of the quality of their evidence suggests that the students can still improve in this respect. Specifically, none of the pairs attained a Level 4 for evidence, whereas only seven of the twenty-six pairs reached a Level 3, the level at which all evidence cited is appropriate, and at which no contradictory or irrelevant data are cited as evidence. Table 6 shows the results for each class.

Table 6 . Scoring of the evidence component of the students' refuted explanations.

\begin{tabular}{|c|c|c|c|c|}
\hline $\begin{array}{c}\text { Level of } \\
\text { evidence }\end{array}$ & $\begin{array}{c}\text { STOCHASMOS inquiry } \\
\text { environment } \\
\text { +WorkSpace } \\
\text { (n=13 pairs) }\end{array}$ & \multicolumn{2}{|c|}{$\begin{array}{c}\text { STOCHASMOS inquiry } \\
\text { environment } \\
\text { + PowerPoint } \\
\text { (n=13 pairs) }\end{array}$} \\
\hline & \# of pairs & Percentage & \# of pairs & $\%$ \\
\hline L4 & 0 & 0 & 0 & 0 \\
\hline L3 & 4 & 31 & 3 & 23 \\
\hline L2 & 3 & 23 & 1 & 8 \\
\hline L1 & 3 & 23 & 3 & 23 \\
\hline L0 & 3 & 23 & 6 & 46 \\
\hline
\end{tabular}

L4: All evidence is sufficient and appropriate.

L3: No contradictory or irrelevant evidence cited. However, the evidence is not sufficient.

L2: Some evidence provided, but not sufficient. Some of it is contradictory and/or false.

L1: Evidence is provided but all evidence is inappropriate.

L0: No evidence provided

Deleted: The levels of evidence correspond to the levels described in more detail in Table 2. Briefly:II

Formatted: Tabs: $468 \mathrm{pt}$, Left + Not at $399.75 \mathrm{pt}$

The findings presented so far, suggest some subtle differences between the two

scaffolding contexts. Next in the paper, we present the results for the second research question,

which investigated the relationship between grouping, scaffolding context and students' collaborative explanations. 


\subsection{Relationship between grouping, scaffolding and explanations}

To examine the effects of the reflective scaffolding and cognitive ability grouping on the pairs' written explanations we used non-parametric statistical tests, due to the small sample size. The hypothesis tested, using the Kruskal Wallis test, was that reflective scaffolding equally supports all grouping situations (high-, low-, and mixed- cognitive ability) to construct explanations of the ecosystem disturbance. The analysis showed that there was no difference between the pairs in the three grouping situations in the WorkSpace reflective scaffolding class for the total explanation score, $\chi^{2}(2)=2.38, p>.05$, the main explanation, $\chi^{2}(2)=4.12, p>.05$, and for the refuted rival explanations, $\chi^{2}(2)=2.50, p>.05$. The same test with the PowerPoint class data indicated a significant difference between the pairs in each grouping situation (high-, low-, and mixed-ability groups) for the measure of the total explanation score, $\chi^{2}(2)=6.109, p<.05$, and the main explanation score, $\chi^{2}(2)=8.390, p<.05$. There was no difference between the pairs for the refuted rival explanations, $\chi^{2}(2)=2.279, p>.05$. Subsequently, a series of Mann Whitney $U$ tests were carried out to provide post-hoc comparisons of the Mean Ranks. These tests showed that there was a significant difference for the main explanation of the Flamingo death problem between the pairs in the homogenous high and homogenous low grouping class $(U=.00, p<.05)$, between the pairs in the mixed and low cognitive ability grouping conditions $(\mathrm{U}=1.0, \mathrm{p}<.05)$, but not between the high and the mixed cognitive ability pairs $(U=4.0, p>.05)$. These findings indicate that the high and mixed cognitive ability pairs outperformed the low cognitive ability ones, but that there were no significant difference between the high and the mixed cognitive ability pairs. Our analysis also shows that initial cognitive ability, as indicated by the results of the Raven's Standard Progressive Matrices (RSPM) and the conceptual understanding test 
(SUE), was not an important factor in differentiating between pairs of students in the WorkSpace class, whereas it was an important factor in differentiating between pairs in the PowerPoint class.

\section{Discussion}

This study set out to examine the relationship between reflective scaffolding, cognitive ability grouping and the quality of students' collaborative explanations of a complex, ecosystem problem. Students in two $6^{\text {th }}$ grade classes worked in homogenous pairs of high, low, and mixed cognitive ability grouping, with each intact class being assigned to one scaffolding context (WorkSpace, PowerPoint). One of the main issues emerging from the analysis of the data was the presence of significant differences between the different groupings in the PowerPoint context, and the corresponding absence of such a difference in the WorkSpace context. Based on these results, it seems that the reflective scaffolding offered through the WorkSpace environment might have more positively contributed to the lower cognitive ability pairs' explanation building process. We discuss the main results of this study next.

\section{The relationship between reflective scaffolding and evidence-based explanations}

When examining the pairs' explanations, we noticed differences between the two scaffolding contexts. These differences were obvious especially when examining whether students included data in support of their claims: on these occasions, it appears that there was a difference in favour of the WorkSpace groups, who more often cited evidence to support their ideas and provided better quality evidence. These findings indicate that the reflective inquiry scaffolding supported students in communicating the data on which they based their decisions. The findings also suggest that designing larger scaffolding structures (e.g. templates) to make the 
requirement of providing evidence explicit to students and giving them the tools to facilitate the linking of evidence can help address problems with communicating evidence reported in other studies (Bell \& Linn, 2000; Sandoval, 2003). Furthermore, beyond the learning benefits that such actions bear for the students, the explicit communication of evidence can support teachers in more validly assessing student understanding and can help create a common ground of communication between the teacher and the students. The latter is crucial, especially in the context of software-based scaffolding that cannot be dynamically adapted to the individual learning needs, as is often the case with much educational software.

At the same time, the analysis of the data highlighted an important challenge our students faced: that of providing sufficient evidence. Such findings suggest that future scaffolding efforts should focus on helping students move beyond identifying data as evidence and focus their reflective conversations on whether the evidence they have is adequate in supporting their claims. The latter has implications regarding the support provided for engaging students in reflective discourse about the data. Several studies, as well as our own experiences, have suggested that students have difficulties in evaluating the quality of the available evidence (McNeill \& Krajcik, 2007; Sandoval \& Millwood, 2005).

\section{Comparing student grouping and evidence-based explanations within scaffolding conditions}

The statistical analysis of students' collaborative explanations in each scaffolding context showed that there were significant differences between the student pairs in the PowerPoint context, but not within the student pairs in the WorkSpace context. Specifically, in the PowerPoint context, there were differences between the main explanation score of the high cognitive ability and mixed cognitive ability pairs and the explanation scores of the low 
cognitive ability pairs, but there were no statistically significant results between the explanation scores of the high-cognitive ability and mixed-cognitive ability pairs. In contrast, we found no statistically significant differences between the pairs in the WorkSpace class. These findings suggest that the pairs' explanations were related to their learning capacity in the case of the PowerPoint class, but that the pairs' learning capacity did not influence the quality of their explanations in the WorkSpace class. The findings also suggest that the scaffolding provided, being one of the main differences between the two learning contexts, might have supported the lower cognitive ability pairs in performing at a similar level as higher cognitive ability pairs. In considering the above conclusion it is important to reflect on possible scaffolding mechanisms that might have helped the students. In both scaffolding contexts, we attempted to change students' task by explicitly integrating reflective inquiry scaffolding to support students' explanation building, as an integral part of students' inquiry activity, either in the WorkSpace or in PowerPoint. Furthermore, we provided more explicit structures and prompts in the WorkSpace to support students in articulating ideas, reflecting on data gathered, and linking data as evidence. The analysis of the data showed that students easily adopted both task structures, and engaged with identifying and documenting data in either environment. What might be the reason for the differences between the two scaffolding contexts? One possible explanation is that the WorkSpace structures within STOCHASMOS, such as the availability of prompts and the explicit task structure to identify, document, and explain data as evidence may have made the explanatory framework explicit to students. One of main structures of the WorkSpace environment is prompting, for which there are several discussions in the literature regarding its effect in promoting understanding (Chi, et al., 1994; Davis, 2003; Duschl, Schweingruber, \& Shouse, 2007). We argue that this scaffolding would be hard to replicate in PowerPoint, whose 
affordances allow for a different task and organizational structure, all meant to allow the user to sequentially organize and present information. In the same way, we believe that a powerful motivator was the coupling of the prompts with the presence of the data to be interpreted. The current study provides evidence regarding the hypothesis that the extent to which software structures can scaffold learning may also depend on students' cognitive ability.

The findings are in line with research arguing that reflective inquiry scaffolding might be more useful to students of lower academic ability, even though it appears that it can also support higher cognitive ability students (B. J. Zimmerman, 1986). It is known that low-achievers benefit by providing and receiving explanations in heterogeneous grouping situations (Swing \& Peterson, 1982), while the quality of low-achieving students' interactions -and thus of learningmay be lower in homogeneous grouping situations. Most of the literature findings on supporting low-achieving students' understanding of higher-order problems point to the need to provide scaffolding by higher-achieving peers or the teacher (Cohen, 1994). However, Zohar \& Dori (2003) argued that it is not uncommon for teachers to underestimate lower learning capacity students and provide low-level support in their interactions with them.

The findings of this study provide evidence for software-based means of supporting students' explanation building, supporting a hypothesis that the reflective inquiry scaffolding used in this study assisted lower cognitive ability students in taking primary responsibility for making sense of ill-structured inquiry investigation data. In this respect, software-based scaffolding that can support low achieving students' collaborative engagement with higher-order reasoning tasks can be seen as a significant partner in supporting higher-order thinking alongside the support offered by the teacher, peers and other external factors. 
When interpreting the results of any study, one also needs to have in mind the study's limitations. One of the limitations of the present work is the small sample size, since only 13 pairs were available to study in each classroom. Even though such issues are common when researching naturalistic situations, such as the real world of classrooms, collecting comparable data from more classrooms would strengthen the results of the study. Furthermore, discourse analyses of students' videotaped conversations and interactions can contribute to a better understanding of the role of software scaffolding in students' inquiry. Such examination can provide more detail in understanding how particular features of the software may have contributed to students' explanation building and may highlight how such tools mediate student activity in context.

\section{Conclusions and implications}

This study examined the relationships between students' cognitive ability grouping and

reflective scaffolding in supporting the collaborative explanation building of $6^{\text {th }}$ grade students, from two intact classes, working collaboratively to solve a complex ecological problem. Both classes used the STOCHASMOS inquiry environment to access rich inquiry data, the student pairs in one class used the STOCHASMOS WorkSpace to organize, interpret and reflect on their data, whereas the students in the other class used PowerPoint, which they freely structured to help them construct evidence-based explanations. To help us examine the role of reflective scaffolding we compared the quality of students' explanations in each class. Findings indicate that the pairs in the WorkSpace class cited evidence to a greater extent, and that the WorkSpace scaffolding supported students' addressing alternative explanations of their data, linking their 
reasoning for refuting these explanations to data they had examined. Findings also show that especially the students in the lower cognitive ability grouping in the WorkSpace benefited from receiving the scaffolding. Such findings indicate that middle-school students can develop evidence-based reasoning with appropriate scaffolding and that all students can start appreciating and participate in the epistemic game of constructing scientific explanations (Collins \& Ferguson, 1993). The findings also indicate that it is possible through instructional design to provide differentiated scaffolding that supports the engagement, reflective participation, and active inquiry of all students in complex, scientific tasks. The results of this study can inform practice, design, and research, as they indicate opportunities for scaffolding students' participation in inquiry learning and contribute to our understanding of the ways in which scaffolding can be effective.

\section{Notes, Acknowledgements}

To be included 
References

Author.

Baker, M., \& Lund, K. (1997). Promoting reflective interactions in a computer-supported collaborative learning environment. Journal of Computer Assisted Learning, 13, 175-193.

Barron, B. (2000). Problem solving in video-based microworlds: Collaborative and individual outcomes of high achieving sixth grade students. Journal of Educational Psychology, 92, 391-398.

Bell, P., \& Linn, M. C. (2000). Scientific arguments as learning artifacts: designing for learning from the web with KIE. International Journal of Science Education, 22(8), 797-817.

Blumenfeld, P., Soloway, E., Marx, R. W., Krajcik, J. S., Guzdial, M., \& Palincsar, A. (1991). Motivating project-based learning: Sustaining the doing, supporting the learning. Educational Psychologist, 26, 369-398.

Bowers, C. A., Pharmer, J. A., \& Salas, E. (2000). When Member Homogeneity is Needed in Work Teams: A Meta-Analysis. Small Group Research, 31(3), 305-327. doi: $10.1177 / 104649640003100303$

Brewer, W. F., Chinn, C. A., \& Samarapungavan, A. (2000). Explanation in scientists and children. In F. C. Keil \& R. A. Wilson (Eds.), Explanation and cognition, 279-298. Cambridge, MA: MIT Press.

Cañas, A. J., Coffey, J. W., Carnot, M. J., Feltovich, P., Hoffman, R. R., Feltovich, J. (2003). Summary of literature pertaining to the use of concept mapping techniques and technologies for education and performance support. Pensacola, FL.

Cheng, R. W.-y., Lam, S.F., \& Chan, J. C.Y. (2008). When high achievers and low achievers work in the same group: The roles of group heterogeneity and processes in project-based learning. British Journal of Educational Psychology, 78, 205-221.

Chi, M. T. H., Bassok, M., Lewis, M. W., Reimann, P., \& Glaser, R. (1989). Self-explanations: How students study and use examples in learning to solve problems. Cognitive Science, $13,145-182$.

Chi, M. T. H., Leeuw, N. d., Chiu, M.-H., \& LaVancher, C. (1994). Eliciting self explanations improves understanding. Cognitive Science, 18(3), 439-477.

Clark, D. J., Weinberger, A., Jucks, R., Spitulnik, M., \& Wallace, R. (2003). Designing Effective Science Inquiry in Text-Based Computer-Supported Collaborative Learning Environments International Journal of Educational Policy, Research, and Practice, 4(1), $55-82$.

Collins, A., \& Ferguson, W. (1993). Epistemic forms and epistemic games: Structures and Strategies to guide inquiry. Educational Psychologist, 28(1), 25-42.

Davis, E. A. (2003). Prompting middle school science students for productive reflection: Generic and directed prompts. The Journal of the Learning Sciences, 12(1), 91-142.

Dillenbourg, P., Baker, M., Blaye, A., \& O' Malley, C. (1996). The evolution of research on collaborative learning. In E. Spada \& P. Reiman (Eds.), Learning in Humans and Machine: Towards an interdisciplinary learning science. (pp. 189-211). Oxford: Elsevier.

de Jong, T. (2006). Scaffolds for computer simulation based scientific discovery learning. In J. Elen \& R. E. Clark (Eds.), Dealing with complexity in learning environments (pp. 107128). Londong: Elsevier Science Publishers. 
de Vries, E., Lund, K., \& Baker, M. (2002). Computer-mediated epistemic dialogue: explanation and argumentation as vehicles for understanding scientific notions. The Journal of the Learning Sciences, 11(1), 63-103.

Deary, I. J., Strand, S., Smith, P., \& Fernandes, C. (2007). Intelligence and educational achievement. Intelligence, 35, 13-21.

Dewey, J. (1910). How we think. New York: Heath.

Dillenbourg, P. (2002). Over-scripting CSCL: The risks of blending collaborative learning with instructional design. In P. A. Kirschner (Ed.), Three worlds of CSCL: Can we support CSCL? 61-91. Heerlen: Open University of the Netherlands.

Duschl, R. A., Schweingruber, H. A., \& Shouse, A. W. (Eds.). (2007). Taking Science to School: Learning and Teaching Science in Grades K-8 National Academies Press Publications.

Fuchs, L. S., Fuchs, D., Kazdan, S., Karns, K., Calhoon, M. B., Hamlett, C. L. (2000). Effects of Workgroup Structure and Size on Student Productivity during Collaborative Work on Complex Tasks. The Elementary School Journal, 100(3), 183-212.

Glassner, A., Weinstock, M., \& Neuman, Y. (2005). Pupils' evaluation and generation of evidence and explanation in argumentation. British Journal of Educational Psychology, $75,105-118$.

Hadjichristoforou, M. (2004). Lead shot at Larnaca salt lake - assessment and restoration activities. Department of Fisheries and Marine Research, Cyprus. Paper presented at the 5th European Regional Meeting on the implementation and effectiveness of the Ramsar Convention. 4-8 December 2004, Yerevan, Armenia

Harskamp, E., Ding, N., \& Suhre, C. (2008). Group composition and its effect on female and male problem-solving in science education. Educational Research, 50(4), 307-318.

Hutchins, E. (1995). Cognition in the wild: MIT Press.

Järvelä, S., Häkkinen, P., Arvaja, M., \& Leinonen, P. (2004). Instructional support in CSCL. In J. W. Strijbos, P. A. Kirschner \& R. L. Martens (Eds.), What we know about CSCL (pp. 115-139). New York: Kluwer Academic Publishers.

Jensen, A. R. (1998). The g factor: The science of mental ability. Westport, CT: Praeger.

Jermann, P., Soller, A., \& Lesgold, A. (2004). Computer software support for CSCL. In J. W. Strijbos, P. A. Kirschner \& R. L. Martens (Eds.), What we know about CSCL, 141-166. Kluwer Academic Publishers.

Jermann, P., Soller, A., \& Lesgold, A. (2007). Computer software support for cscl In H. U. Hoppe, H. Ogata \& A. Soller (Eds.), The Role of Technology in CSCL: Studies in Technology Enhanced Collaborative Learning:Studies in Technology Enhanced Collaborative Learning, 141-166. Springer US.

Johnson, D. W., \& Johnson, R. T. (1989). Cooperation and competition: Theory and research: Interaction Book Company.

Johnson, D. W., Johnson, R. T., \& Stanne, M. B. (2000). Cooperative Learning Methods: A Meta-Analysis. Retrieved December 10, 2009, from http://www.cooperation.org/pages/cl-methods.html

Krajcik, J. (2003). The value and challenges of using learning technologies to support students in learning science. Research in Science education, 32, 411-414.

Krajcik, J., Blumenfeld, P., Marx, R., Bass, K. M., \& Fredricks, J. (1998). Inquiry in projectbased science classrooms: initial attempts by middle school students. The Journal of the Learning Sciences, 7(3\&4), 313-350. 
Kreijns, K., Kirschner, P. A., \& Jochems, W. (2003). Identifying the pitfalls for social interaction in computer-supported collaborative learning environments. A review of the research. Computers in Human Behavior, 19(3), 335-353.

Kuhn, D., Amsel, E., \& O'Loughlin, M. (1988). The development of scientific thinking skills. San Diego: Academic Press.

Kutnick, P., \& Thomas, M. (1990). Dyadic Pairings for the Enhancement of Cognitive Development in the School Curriculum: Some Preliminary Results on Science Tasks. British Educational Research Journal, 16(4), 399-406.

Linn, M. C. (2003). Technology and science education: starting points, research programs, and trends. International Journal of Science Education, 25(6), 727-758.

Linn, M. C., Clark, D., \& Slotta, J. D. (2003). WISE design for knowledge integration. Science Education, 87(4), 517-538.

Linn, M. C., Davis, E. A., \& Bell, P. (Eds.). (2004). Internet Environments for Science Education. Mahwah, New Jersey: Lawrence Erlbaum Associates, Publishers.

Loh, B. (2003). Using articulation and inscription as catalysts for reflection: design principles for reflective inquiry. Ph.D. dissertation, Northwestern University, Evanston, IL.

Loh, B., Radinsky, J., Reiser, B. J., Gomez, L., Edelson, D. C., \& Russell, E. (1997). The Progress Portfolio: Promoting reflective inquiry in complex investigation environments. In R. Hall, N. Miyake \& N. Enyedy (Eds.), Proceedings of Computer Supported Collaborative Learning '97, 169-178. Toronto, Ontario, Canada.

Loh, B., Reiser, B. J., Radinsky, J., Edelson, D. C., Gomez, L. M., \& Marshall, S. (2001). Developing Reflective Inquiry Practices: A Case Study of Software, the Teacher, and Students. In S. K. Crowley, C. Schunn \& T. Okada (Eds.), Designing for Science: Implications from Everyday, Classroom, and Professional Settings. Mahwah, NJ: Erlbaum.

Manlove, S., Lazonder, A. W., \& De Jong, T. (2006). Regulative support for collaborative scientific inquiry learning Journal of Computer Assisted Learning, 22, 87-98.

McNeill, K. L., \& Krajcik, J. (2007). Middle school students' use of appropriate and inappropriate evidence in writing scientific explanations. In M. Lovett \& P. Shah (Eds.), Thinking with Data: the Proceedings of the 33rd Carnegie Symposium on Cognition. Mahwah, NJ: Lawrence Erlbaum Associates, Inc.

McNeill, K. L., \& Krajcik, J. (2007). Middle school students' use of appropriate and inappropriate evidence in writing scientific explanations. In M. Lovett \& P. Shah (Eds.), Thinking with Data: the Proceedings of the 33rd Carnegie Symposium on Cognition. Mahwah, NJ: Lawrence Erlbaum Associates, Inc.

McNeill, K. L., Lizotte, D. J., Krajcik, J., \& Marx, R. W. (2006). Supporting students' construction of scientific explanations by fading scaffolds in instructional materials. The Journal of the Learning Sciences, 15(2), 153-191.

Mynatt, C. R., Doherty, M. E., \& Tweney, R. D. (1977). Confirmation bias in a simulated research environment: an experimental study of scientific inference. In P. N. JohnsonLaird \& P. C. Wason (Eds.), Thinking: Readings in Cognitive Science, 315-325. Cambridge: Cambridge University Press.

NRC (1996). National science education standards. Washington, D. C.: National Academy Press. 
O'Donnell, A. M. (2006). The role of peers and group learning. In P. Alexander \& P. Winne (Eds.), Handbook of educational psychology (2nd ed.), 781-802. Mahwah, NJ: Lawrence Erlbaum.

Quintana, C., Eng, J., Carra, A., Wu, H., \& Soloway, E. (1999). Symphony: A case study in extending learner-centered design through process-space analysis. Proceedings of CHI 99 Conference on Human Factors in Computing Systems, 473-480.

Quintana, C., Reiser, B. J., Davis, E. A., Krajcik, J., Fretz, E., Duncan, R. G. Et al. (2004). A scaffolding design framework for software to support science inquiry. The Journal of the Learning Sciences, 13(3), 337-386.

Reiser, B. J. (2004). Scaffolding complex learning: the mechanisms of structuring and problematizing student work. The Journal of the Learning Sciences, 13(3), 273-304.

Reiser, B. J., Tabak, I., Sandoval, W. A., Smith, B. K., Steinmuller, F., \& Leone, A. J. (2001). BGuILE: Strategic and conceptual scaffolds for scientific inquiry in biology classrooms. In S. M. C. D. Klahr (Ed.), Cognition and instruction: Twenty-five years of progress, 263-305. Mahwah, NJ: Erlbaum.

Rogoff, B. (2008). Observing Sociocultural activity on three planes: Participatory appropriation, guided participation, and apprenticeship. In K. Hall, P. Murphy \& J. Soler (Eds.), Pedagogy and Practice: Culture and Identities: Sage Publications.

Rohde, T. E., \& Thompson, L. A. (2007). Predicting academic achievement with cognitive ability. Intelligence(35), 83-92.

Ruiz-Primo, M. A., Schultz, S. E., Li, M., \& Shavelson, R. J. (2001). Comparison of the reliability and validity of scores from two concept-mapping techniques. Journal of Research in Science Teaching, 38(2), 260-278.

Sadler, T. D. (2004). Informal reasoning regarding socioscientific issues: a critical review of research. Journal of Research in Science Teaching, 41(5), 513-536.

Saleh, M., Lazonder, A. W., \& Jong, T. d. (2007). Structuring collaboration in mixed-ability groups to promote verbal interaction, learning, and motivation of average-ability students. Contemporary Educational Psychology, 32(3), 314-331.

Salmon, W. C. (1989). Four Decades of Scientific Explanations: University of Minnesota Press.

Salomon, G., Perkins, D. N., \& Globerson, T. (1991). Partners in cognition: Extending human intelligence with intelligent technologies. Educational Researcher, 20(3), 2-9.

Sandoval, W. A. (1998). ExplanationConstructor [Computer software]. Evanston, IL: Northwestern University.

Sandoval, W. A. (2003). Conceptual and epistemic aspects of students' scientific explanations. Journal of the Learning Sciences, 12(1), 5-51.

Sandoval, W. A. (2005). Understanding students' practical epistemologies and their influence on learning through inquiry. Science Education, 89(4), 634-656.

Sandoval, W. A., \& Millwood, K. A. (2005). The quality of students' use of evidence in written scientific explanations. Cognition and Instruction, 23(1), 23-55.

Sandoval, W. A., \& Reiser, B. J. (2004). Explanation-driven inquiry: integrating conceptual and epistemic scaffolds for scientific inquiry. Science Education, 88, 345-372.

Scardamalia, M., \& Bereiter, C. (1994). Computer support for knowledge-building communities. The Journal of the Learning Sciences, 3, 265-283.

Slavin, R. (1990). Cooperative learning: Theory, research and practice. Englewood Cliffs, NJ: Prentice Hall. 
Soller, A., Martinez, A., Jermann, P., \& Muehlenbrock, M. (2005). From Mirroring to Guiding: A Review of State of the Art Technology for Supporting Collaborative Learning. International Journal of Artificial Intelligence in Education, 15, 261-290.

Stahl, G., Koschmann, T., \& Suthers, D. D. (2006). Computer-Supported Collaborative Learning: An historical perspective. In R. K. Sawyer (Ed.), The Cambridge Handbook of the Learning Sciences, 409-425: Cambridge University Press.

Suthers, D. D. (2001). Towards a Systematic Study of Representational Guidance for Collaborative Learning Discourse. Journal of Universal Computer Science. , 7(3), 254277.

Suthers, D. D., \& Jones, D. (1997). An architecture for intelligent collaborative educational systems. Paper presented at the AI-Ed 97, the 8th World Conference on Artificial Intelligence in Education, Kobe, Japan.

Suthers, D. D., \& Weiner, A. (1995). Groupware for developing critical discussion skills. . Paper presented at the CSCL '95 Computer Supported Cooperative Learning, Bloomington, Indiana.

Tabak, I. (2004). Synergy: A Complement to Emerging Patterns of Distributed Scaffolding. Journal of the Learning Sciences, 13(3), 305-355.

Tabak, I., Sandoval, W. A., Reiser, B. J., \& Steinmuller, F. (2000). The Galapagos Finches. In J. J. V. Vaughan (Ed.), Bioquest Library Volume VI. San Diego, CA: Academic Press.

Toth, E. E., Suthers, D. D., \& Lesgold, A. M. (2002). "Mapping to Know": The Effects of Representational Guidance and Reflective Assessment on Scientific Inquiry. Science Education, 86(2), 264-286.

Toulmin, S. E. (1958). The uses of argument: Cambridge [Eng.] University Press.

Webb, N. M. (1982). Peer interaction and learning in cooperative small groups. Journal of Educational Psychology, 74(5), 642-655.

Webb, P., \& Treagust, D. F. (2006). Using Exploratory Talk to Enhance Problem-solving and Reasoning Skills in Grade-7 Science Classrooms. Research in science education, 36, 381-401.

Wu, H. K., \& Hsieh, C. E. (2006). Developing Sixth Graders' Inquiry Skills to Construct Explanations in Inquiry-based Learning Environments. International Journal of Science Education, 28(11), 1289 - 1313.

Yin, Y., Vanides, J., Ruiz-Primo, M. A., Ayala, C. C., \& Shavelson, R. J. (2005). Comparison of two concept-mapping techniques: Implications for scoring, interpretation, and use. Journal of Research in Science Teaching, 42(2), 166-184.

Zimmerman, B. J. (1986). Becoming a self-regulated learner: which are the key subprocesses? Contemporary Educational Psychology(11), 307-313.

Zimmerman, B. J. (2002). Becoming a self-regulated learner: An overview. Theory into Practice, 4l(2), 64-70.

Zimmerman, C. (2000). The development of scientific reasoning skills. Developmental Review, 20, 99-149.

Zimmerman, C. (2005). The development of scientific reasoning skills: What psychologists contribute to an understanding of elementary science learning. Final Draft of a Report to the National Research Council Committee on Science Learning Kindergarten through Eighth Grade, 1-109.

Zohar, A., \& Dori, Y. J. (2003). Higher order thinking skills and low-achieving students: are they mutually exclusive? The Journal of the Learning Sciences, 12(2), 145-181. 
1

2

3

4

5

6

7

8

9

10

11

12

13

14

15

16

17

18

19

20

21

22

23

24

25

26

27

28

29

30

31

32

33

34

35

36

37

38

39

40

41

42

43

44

45

46

47

48

49

50

51

52

53

54

55

56

57

58

59

60

Zuzovsky, R., \& Tamir, P. (1999). Growth patterns in students' ability to supply scientific explanations: findings from the Third International Mathematics and Science Study in Israel. International Journal of Science Education, 21(10), 1101-1121. 


\title{
Prompting provided for the WorkSpace and the PowerPoint class
}

\author{
A. Prompting which was similar in both conditions (provided by the teacher) \\ 1. Create an evidence-based explanation \\ 2. Write down three hypotheses about what might have led to the death of the Flamingos \\ 3. Collect evidence from the inquiry environment to investigate your hypotheses. \\ 4. Write an explanation indicating what may have caused the Flamingo death and which \\ hypotheses you refuted.
}

\section{B. STOCHASMOS WorkSpace prompts}

Students in the STOCHASMOS WorkSpace condition had three template pages available to them (hypothesis page, data page, explanation page). Screenshots of each of the template pages are provided in the next pages. Students could create an unlimited number of each of the template pages, which they could use to organize and articulate their explanations. There was no limitation set in terms of how many pages they could create. 


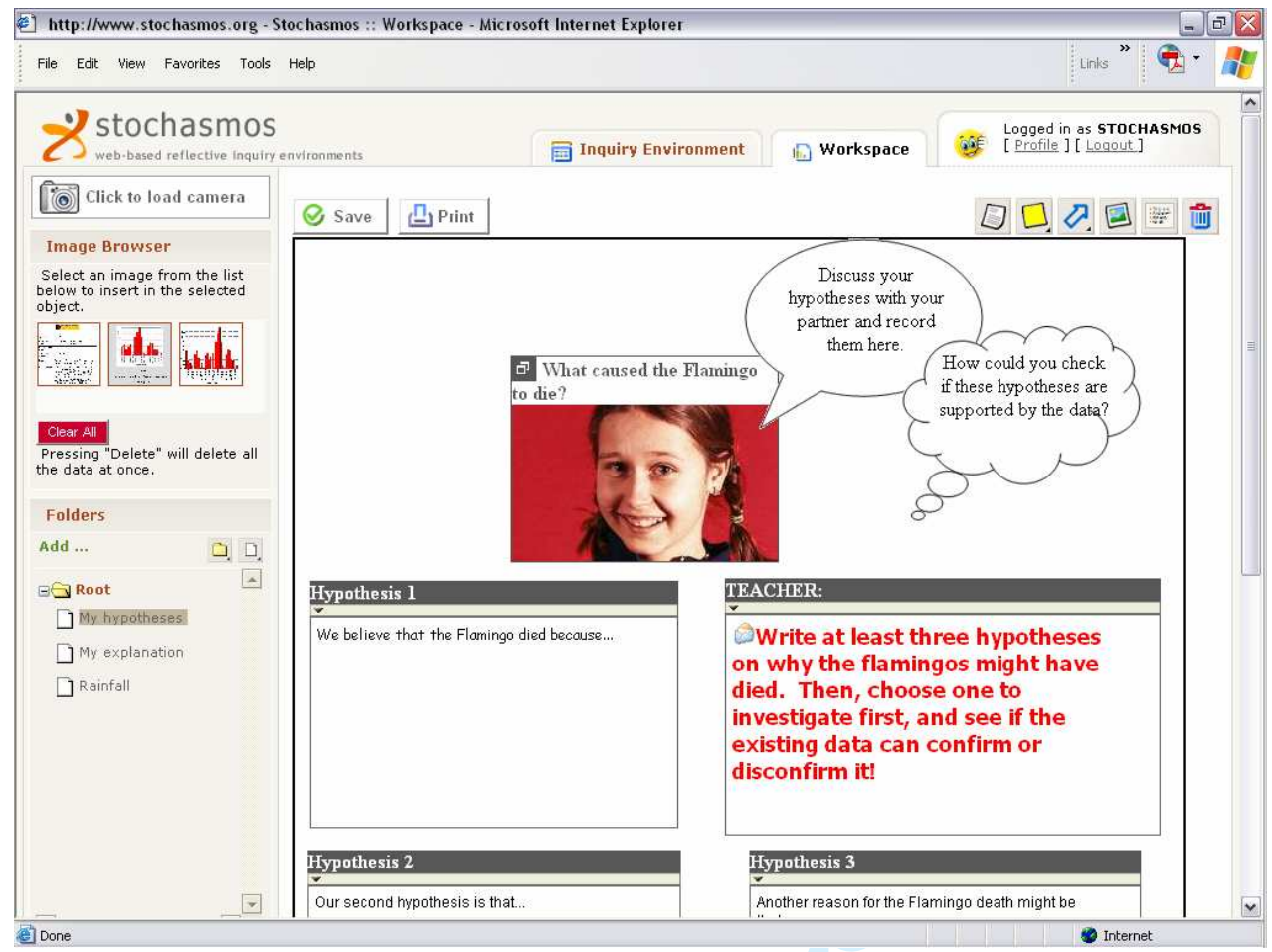

Figure 5: Hypothesis page template prompts 


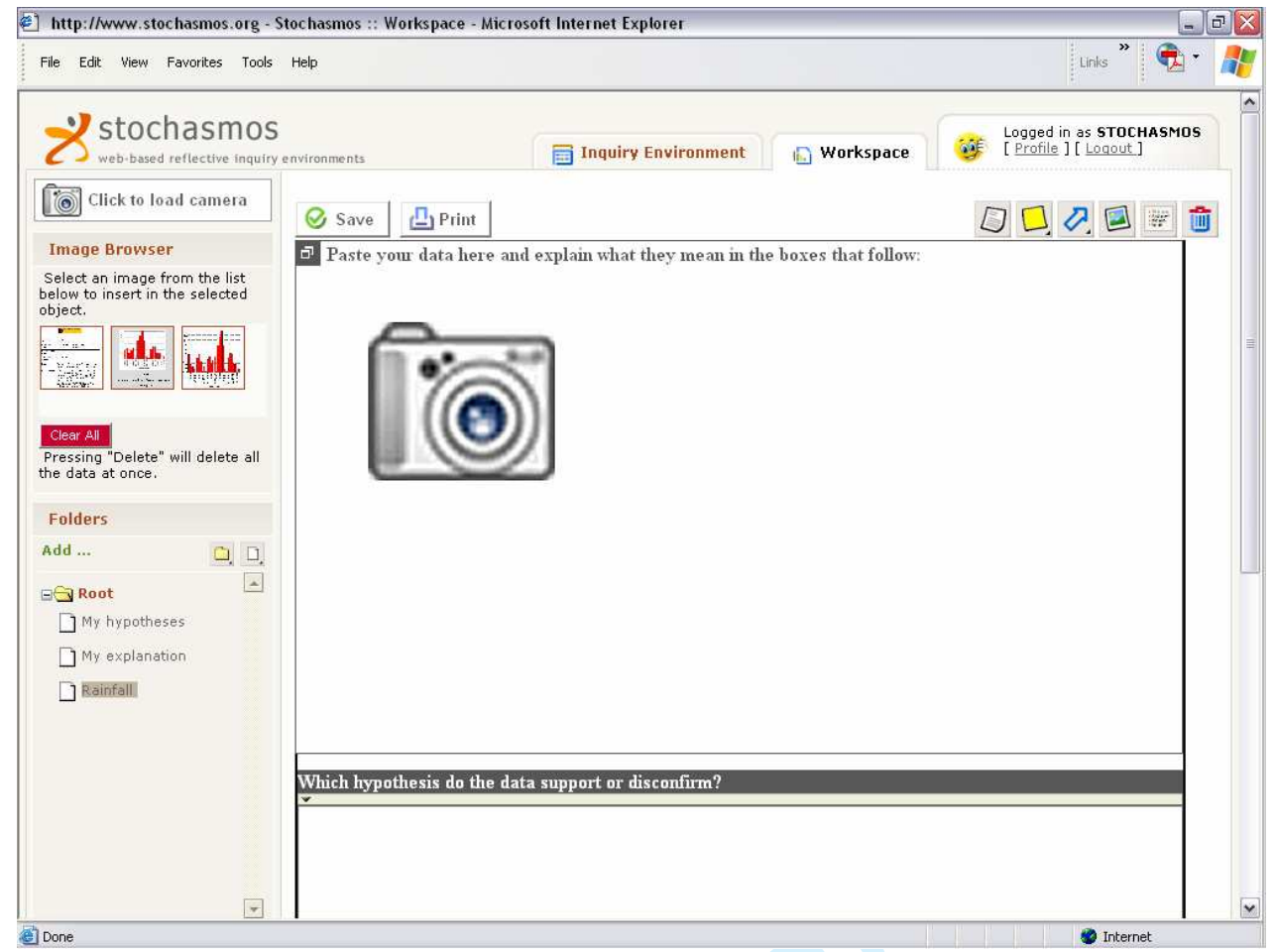

Figure 6: Data page template prompts 


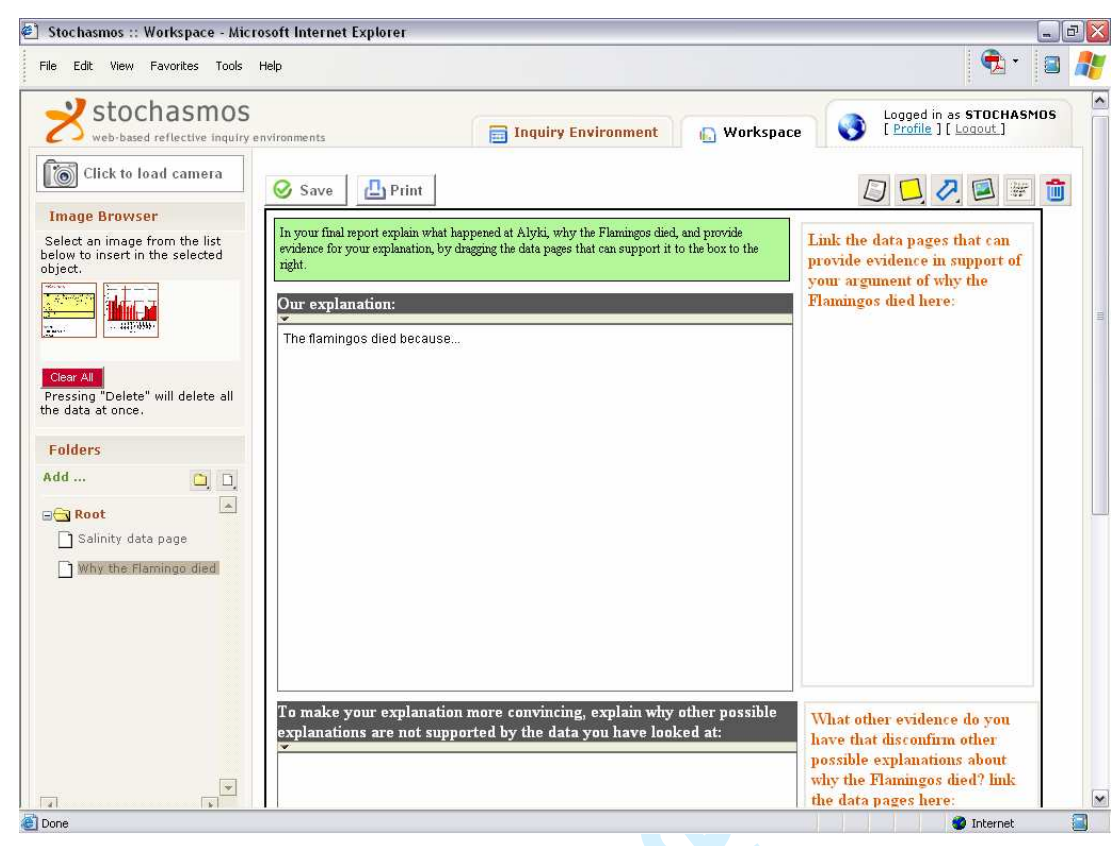

Figure 7: Explanation page template prompts

\section{PowerPoint prompts}

No other prompting was embedded in PowerPoint. There was no limitation set in terms of how many PowerPoint pages students could create. 
Table 7. The Flamingo explanation coding scheme. 


\begin{tabular}{|c|c|c|c|c|c|c|}
\hline & Level & & & & & \\
\hline $\begin{array}{c}\text { Main } \\
\text { explanation }\end{array}$ & $\mathbf{0}$ & 1 & 2 & 3 & 4 & 5 \\
\hline & & & & $\begin{array}{l}\text { Some false } \\
\text { reasoning may } \\
\text { also exist. }\end{array}$ & & \\
\hline $\begin{array}{l}\text { Evidence cited } \\
\text { (explicitly } \\
\text { linking the } \\
\text { claim about } \\
\text { the death of } \\
\text { the flamingos } \\
\text { with } \\
\text { investigation } \\
\text { data) }\end{array}$ & $\begin{array}{l}\text { The group } \\
\text { has not } \\
\text { provided any } \\
\text { evidence to } \\
\text { support their } \\
\text { claim as to } \\
\text { why the } \\
\text { flamingos } \\
\text { die or may } \\
\text { cite as } \\
\text { evidence } \\
\text { background } \\
\text { data. }\end{array}$ & $\begin{array}{l}\text { The group } \\
\text { has provided } \\
\text { evidence } \\
\text { explicitly } \\
\text { supporting } \\
\text { their claim } \\
\text { but all } \\
\text { evidence } \\
\text { linked is not } \\
\text { appropriate. }\end{array}$ & $\begin{array}{l}\text { The group } \\
\text { provided } \\
\text { some } \\
\text { evidence but } \\
\text { some of the } \\
\text { evidence is } \\
\text { contradictory } \\
\text { or/and false. } \\
\text { The evidence } \\
\text { provided is } \\
\text { not sufficient } \\
\text { to support the } \\
\text { claim. }\end{array}$ & $\begin{array}{l}\text { The group has } \\
\text { provided } \\
\text { evidence in } \\
\text { support of } \\
\text { their claim. } \\
\text { There is no } \\
\text { contradictory } \\
\text { or irrelevant } \\
\text { evidence cited, } \\
\text { and the } \\
\text { evidence is all } \\
\text { appropriate. } \\
\text { The group has } \\
\text { linked their } \\
\text { claim and the } \\
\text { evidence cited. } \\
\text { However, the } \\
\text { evidence is not } \\
\text { sufficient to } \\
\text { support the } \\
\text { claim stated. }\end{array}$ & $\begin{array}{l}\text { The group has } \\
\text { provided } \\
\text { evidence in } \\
\text { support of their } \\
\text { claim. All } \\
\text { evidence } \\
\text { provided is } \\
\text { sufficient and } \\
\text { appropriate. } \\
\text { The group has } \\
\text { linked the } \\
\text { evidence cited } \\
\text { and their claim } \\
\text { stated. }\end{array}$ & \\
\hline \multicolumn{7}{|l|}{$\begin{array}{l}\text { Rival } \\
\text { explanations }\end{array}$} \\
\hline $\begin{array}{l}\text { Listed other } \\
\text { explanations } \\
\text { they refuted }\end{array}$ & $\begin{array}{l}\text { The group } \\
\text { has not listed } \\
\text { any rival } \\
\text { explanations } \\
\text { they have } \\
\text { refuted. }\end{array}$ & $\begin{array}{l}\text { The group } \\
\text { has listed one } \\
\text { or more rival } \\
\text { explanations } \\
\text { they have } \\
\text { attempted to } \\
\text { refute. }\end{array}$ & & & 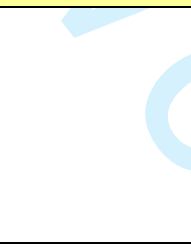 & \\
\hline
\end{tabular}




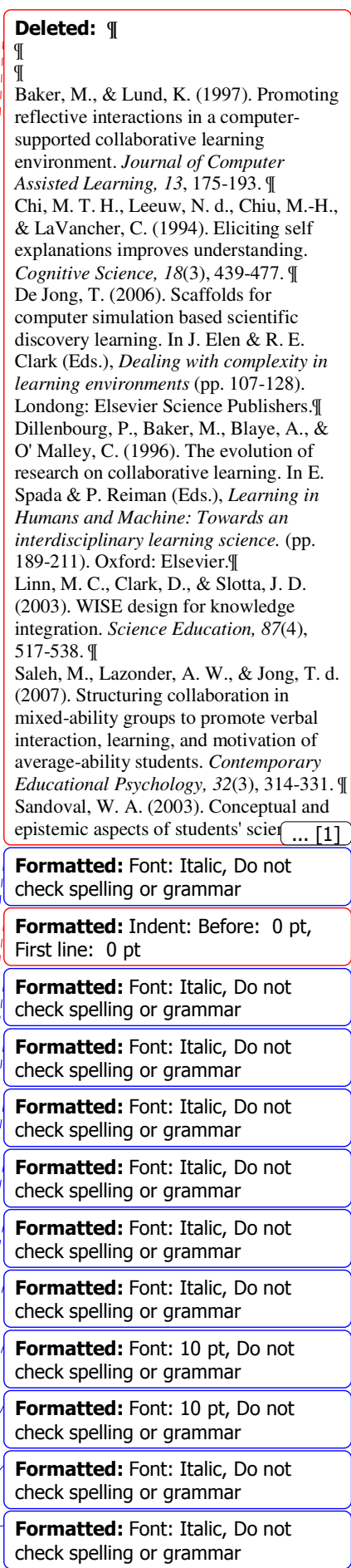

Cited evidence in support of the refutation of the rival explanations
The group has not provided any reasons for refuting the rival explanations they listed.

The group provided no evidence to support their refutation of rival explanations.

\begin{tabular}{|l|l|l|l|l|} 
& & & & \\
\hline 1 & 2 & 3 & 4 & 5 \\
\hline
\end{tabular}

The group

has

explained

their

to why they

refuted some

or all of the

rival

explanations.

However, the

rationale

provided in

each case is

irrelevant or

insufficiently

elaborated

for all the

refuted claims.

The group has provided evidence to support the reason they refuted a rival explanation but all evidence linked is not appropriate.

The group has provided a rationale as to why at least some of the rival explanations listed were refuted. However, the rationale behind rejecting some of the explanations may be missing or not described adequately.
The group provided evidence for some or all of the alternative explanations they have refuted. One or more of the following may hold true: some of this evidence may not be relevant, appropriate, based on the information that was available. The evidence may not be clearly connected to particular counteror sufficient,
The provided a for all the rival The group has provided relevant evidence in support of their refuted explanations. There is no contradictory or irrelevant evidence cited, and the evidence is all appropriate. The group has explained the connection between the alternative explanations and the evidence cited. However, the evidence may not be sufficient or well-justified to support the claim or claims stated.
The group has provided evidence in support of their refutation of alternative explanations. All evidence provided is sufficient and appropriate. The group has explained the connection between the evidence cited and the refuted claim. 
Baker, M., \& Lund, K. (1997). Promoting reflective interactions in a computer-supported collaborative learning environment. Journal of Computer Assisted Learning, 13, 175-193. Chi, M. T. H., Leeuw, N. d., Chiu, M.-H., \& LaVancher, C. (1994). Eliciting self explanations improves understanding. Cognitive Science, 18(3), 439-477. De Jong, T. (2006). Scaffolds for computer simulation based scientific discovery learning. In J. Elen \& R. E. Clark (Eds.), Dealing with complexity in learning environments (pp. 107-128). Londong: Elsevier Science Publishers.

Dillenbourg, P., Baker, M., Blaye, A., \& O' Malley, C. (1996). The evolution of research on collaborative learning. In E. Spada \& P. Reiman (Eds.), Learning in Humans and Machine: Towards an interdisciplinary learning science. (pp. 189-211). Oxford: Elsevier.

Linn, M. C., Clark, D., \& Slotta, J. D. (2003). WISE design for knowledge integration. Science Education, 87(4), 517-538.

Saleh, M., Lazonder, A. W., \& Jong, T. d. (2007). Structuring collaboration in mixedability groups to promote verbal interaction, learning, and motivation of average-ability students. Contemporary Educational Psychology, 32(3), 314-331.

Sandoval, W. A. (2003). Conceptual and epistemic aspects of students' scientific explanations. Journal of the Learning Sciences, 12(1), 5-51.

Sandoval, W. A. (2003). The inquiry paradox: why doing science doesn't necessarily change ideas about science. In C. P. Constantinou \& Z. C. Zacharia (Eds.), Proceedings of the Sixth International Computer-Based Learning in Science Conference (pp. 825-834). Nicosia, Cyprus. Webb, N. M. (1982). Peer interaction and learning in cooperative small groups. Journal of Educational Psychology, 74(5), 642-655.

Baker, M., \& Lund, K. (1997). Promoting reflective interactions in a computer-supported collaborative learning environment. Journal of Computer Assisted Learning, 13, 175-193. Chi, M. T. H., Leeuw, N. d., Chiu, M.-H., \& LaVancher, C. (1994). Eliciting self explanations improves understanding. Cognitive Science, 18(3), 439-477.

De Jong, T. (2006). Scaffolds for computer simulation based scientific discovery learning. In J. Elen \& R. E. Clark (Eds.), Dealing with complexity in learning environments (pp. 107-128). Londong: Elsevier Science Publishers. Dillenbourg, P., Baker, M., Blaye, A., \& O' Malley, C. (1996). The evolution of research on collaborative learning. In E. Spada \& P. Reiman (Eds.), Learning in Humans and Machine: Towards an interdisciplinary learning science. (pp. 189-211). Oxford: Elsevier. 
Linn, M. C., Clark, D., \& Slotta, J. D. (2003). WISE design for knowledge integration. Science Education, 87(4), 517-538.

Saleh, M., Lazonder, A. W., \& Jong, T. d. (2007). Structuring collaboration in mixedability groups to promote verbal interaction, learning, and motivation of average-ability students. Contemporary Educational Psychology, 32(3), 314-331.

Sandoval, W. A. (2003). Conceptual and epistemic aspects of students' scientific explanations. Journal of the Learning Sciences, 12(1), 5-51.

Sandoval, W. A. (2003). The inquiry paradox: why doing science doesn't necessarily change ideas about science. In C. P. Constantinou \& Z. C. Zacharia (Eds.), Proceedings of the Sixth International Computer-Based Learning in Science Conference (pp. 825-834).

Nicosia, Cyprus.

Sandoval, W. A., \& Reiser, B. J. (2004). Explanation-driven inquiry: integrating conceptual and epistemic scaffolds for scientific inquiry. Science Education, 88, 345-372. Webb, N. M. (1982). Peer interaction and learning in cooperative small groups. Journal of Educational Psychology, 74(5), 642-655. 